\title{
How Do the Nucleons Pack in an Atomic Nucleus?
}

\author{
Xiaodong Li*, Qijun Liu, Gongyi Li, Yihe Li, Zengyong Chu \\ Department of Chemistry and Biology, College of Science, National University of Defense Technology, \\ Changsha, China \\ Email: ${ }^{*}$ xdli0153@sina.com
}

Received 1 August 2014; revised 15 September 2014; accepted 2 October 2014

Copyright (C) 2014 by authors and Scientific Research Publishing Inc.

This work is licensed under the Creative Commons Attribution International License (CC BY). http://creativecommons.org/licenses/by/4.0/

(c) (i) Open Access

\section{Abstract}

A nuclear structure model of "ring plus extra nucleon" is proposed. For nuclei larger than ${ }^{4} \mathrm{He}$, protons (P) and neutrons (N) are basically bound alternatively to form a $Z \mathrm{P}+Z \mathrm{~N}$ ring. The ring folds with a "bond angle" of $90^{\circ}$ for every 3 continuous nucleons to make the nucleons packed densely. Extra N('s) can bind to ring-P with the same "bond angle" and "bond distance". When 2 or more $P$ 's are geometrically available, the extra $N$ tends to be stable. Extra $P$ can bind with ring $N$ in a similar way when the ratio of $\mathrm{N} / \mathrm{P}<1$ although the binding is weaker than that of extra $\mathrm{N}$. Even-Z rings, as well as normal even-even nuclei, always have superimposed gravity centers of $P$ and $N$; while for odd- $Z$ rings, as well as all odd- $A$ ( $A$ : number of nucleon) nuclei, the centers of $\mathrm{P}$ and $\mathrm{N}$ must be eccentric. The eccentricity results in a depression of binding energy $\left(E_{B}\right)$ and therefore odd and even $Z$ dependent zigzag features of $E_{\mathrm{B}} / A$. This can be well explained by the shift of eccentricity by extra nucleons. Symmetrical center may present in even- $Z$ rings and normal even-even nuclei. While for odd- $Z$ ring, only antisymmetric center (every $P$ can find an $\mathrm{N}$ through the center and vice versa) is possible. Based on this model, a pair of mirror nuclei, $P_{X+n} N_{X}$ and $P_{X} N_{X+n}$, should be equivalent in packing structure just like black-white photo and the negative film. Therefore, an identical spin and parity was confirmed for any pair. In addition, the $E_{\mathrm{B}} / A$ difference of mirror nuclei pair is nearly a constant of $0.184 \mathrm{n} \mathrm{MeV}$. Many other facts can also be easily understood from this model, such as the neutron halo, the unusual stability sequence of ${ }^{9} \mathrm{Be},{ }^{7} \mathrm{Be}$ and ${ }^{8} \mathrm{Be}$ and so on.

\section{Keywords}

Nuclear Structure, Ring plus Extra Nucleon Model, Nuclear Symmetricity

\section{Introduction}

The packing model of the nucleons in an atomic nucleus always arouses curiosity of many scientists and ama-

${ }^{*}$ Corresponding author. 
teurs. The model determines the shape of a nucleus as well as its various properties, such as the stability, the magnetic moment, the spin, the binding energy and radioactivity. Sophisticated theories of nuclear model were established and many facts were well explained [1] [2]. However, there is obviously still a mysterious veil on some characteristics of nuclei to be revealed, especially the packing structure of nucleons inside a nucleus. Thanks to X-ray diffraction, chemists know plenty of details about how atoms pack to build a molecule. Molecular structure establishes the basis of modern chemistry. However, since nuclei are too small and are usually embedded in electron "cloud", it is very hard to "see" them.

In nature, the equilibrium shape of a centered direction-independent object is a sphere. These objects vary vastly in composition and size, including planets, liquid droplet, bubble, most nucleoli in cell, crystalline spherulite, latex micelles, isolated atoms (at least those which can be packed in cubic lattices) and possibly some elementary particles. A plant leaf is far from a sphere because the petiole to the stem and the surface toward the sun are very direction-related. The non-sphere shape of a molecule comes from the direction-related chemical bonds. Many atomic nuclei are generally not sphere and may possess remarkable non-zero quadrupole moment [2]. That means tha the nucleons, protons $(\mathbf{P})$ and neutrons $(\mathbf{N})$ are bound in specific direction and are packed in a particular structure. In this paper, the authors try to propose a model that depicts the packing of nucleons in a nucleus based on the conception of covalent molecule configuration.

\section{The Binding of Proton and Neutron in a Nucleus}

From the reported data [3]-[5], there are 7 isotopes of hydrogen, or single-P nuclides: ${ }^{1} \mathrm{H},{ }^{2} \mathrm{H},{ }^{3} \mathrm{H},{ }^{4} \mathrm{H},{ }^{5} \mathrm{H},{ }^{6} \mathrm{H}$ and ${ }^{7} \mathrm{H}$. In addition, reported single- $\mathbf{N}$ nuclei include ${ }^{2} \mathrm{H},{ }^{3} \mathrm{He},{ }^{4} \mathrm{Li},{ }^{5} \mathrm{Be}$ and ${ }^{6} \mathrm{~B}$. This gives a clue that $\mathbf{N}$, as well as $\mathbf{P}$, can be a 6-coordinate center bound with 6 "ligands" at maximum as shown in Figure 1(a), where the proper octahedral structure seems to be a right way to ensure the ligands to be indistinguishable. Although these structures need to be further verified, especially the $90^{\circ}$ triangular ${ }^{3} \mathrm{H}$ and ${ }^{3} \mathrm{He}$, it is obvious that, in the case of single center, when the "coordination number" is higher than 2, the isotope will be unstable and tends to kick out the excess $\mathbf{P}$ or $\mathbf{N}$.

Based on these structures, we assume that $\mathbf{P}$ can only bind with $\mathbf{N}$ and vice versa (considering deuterium, $\mathbf{P N}$, is stable, but there is no conclusive evidence about the existence of $\mathbf{N N}$ and $\mathbf{P P}$ ). The "bond distance" between bound $\mathbf{P}$ and $\mathbf{N}, D_{\mathrm{NP}}$, is in the range of 1 to $2 \mathrm{fm}$, and the "bond angle" for 3 continuous nucleons is $90^{\circ}$ or $180^{\circ}$.

The single-center nuclei are characterized by extremely low binding energy $E_{\mathrm{B}}$ (and therefore a low $E_{\mathrm{B}} / A$ ), even for the stable nuclei as ${ }^{2} \mathrm{H}$ and ${ }^{3} \mathrm{He}$, noted in Figure 1(a) comparing with other nuclei. This is probably because of the existence of suspending open $\mathbf{P}$ or open $\mathbf{N}$. Therefore, we assume that, for a nucleus with ratio of $\mathbf{N}: \mathbf{P}=1$, open nucleon should be avoided and all $\mathbf{P}$, as well as all $\mathbf{N}$, should be equivalent. Thus, $\mathbf{P}$ and $\mathbf{N}$ should be bound alternatively to form a ring. It is obviously that the ring is not shaped like a pearl necklace on neck; instead, the ring must fold somehow, like a necklace in casket. The most possible way of folding a ring is taking a "bond angle" of $90^{\circ}$ for every 3 continuous nucleons, to ensure the nuclide to adopt the densest packing and the most nearly sphere symmetrical shape. However, for most nuclei, the ratio of $\mathbf{N} / \mathbf{P}$ is more or less than unit. Among hundreds of stable nuclei, only 12 are composed purely of a ring: ${ }^{4} \mathrm{He},{ }^{6} \mathrm{Li},{ }^{10} \mathrm{~B},{ }^{12} \mathrm{C},{ }^{14} \mathrm{~N},{ }^{16} \mathrm{O},{ }^{20} \mathrm{Ne},{ }^{24} \mathrm{Mg}$, ${ }^{28} \mathrm{Si},{ }^{32} \mathrm{~S},{ }^{36} \mathrm{Ar}$ and ${ }^{40} \mathrm{Ca}$. Thus, extra $\mathbf{N}($ 's) or extra $\mathbf{P}($ 's) will be necessary to connect or insert the ring somehow in most nuclei.

\section{Ring Structure}

Based on the "ring plus extra nucleon" hypothesis, the shape of ${ }^{4} \mathrm{He}$ should be a square, which is the smallest ring. Figure 1(b) demonstrates the shapes and $E_{\mathrm{B}}$ of nuclei of the $\mathbf{P}_{2} \mathbf{N}_{2}$ family, where the extra open $\mathbf{N}$ generally contributes very little to $E_{\mathrm{B}}$, while extra open $\mathbf{P}$ generally gives minus contribution. Thus, in the $\mathbf{P}_{2} \mathbf{N}_{2}$ family, all the nuclei which possess open nucleon are unstable. In addition, the $E_{\mathrm{B}}$ and life time of $\mathbf{P}_{2} \mathbf{N}_{2+X}$ are always in larger number than $\mathbf{P}_{2+X} \mathbf{N}_{2}$. This corresponds to the fact that stable nuclei present a ratio $\mathbf{N} / \mathbf{P} \geq 1$ (except ${ }^{3} \mathrm{He}$ ).

In Figure 1(b), some nuclei may have 2 or more isomers, for example, ${ }^{5} \mathrm{He}$ may have 2 isomers, ${ }^{6} \mathrm{He} 3,{ }^{7} \mathrm{He} 6$ and so on. It is reasonable to assume that favored structure should be the highest symmetry and the most compact. It should be noted that, for saturating the 6 coordinates, ${ }^{12} \mathrm{He}$ will be the possibly heaviest isotope of helium $\left({ }^{10} \mathrm{He}\right.$ is the maximum found). For the same reason, for elements of $Z=7$ to $10,{ }^{9} \mathrm{~N},{ }^{10} \mathrm{O},{ }^{11} \mathrm{~F}$ and ${ }^{12} \mathrm{Ne}$ will be the possibly lightest isotopes respectively, which have not been found yet.

Figure 2 gives the possible shapes of some light rings and their stable isotopes. For odd- $Z$ rings, although 


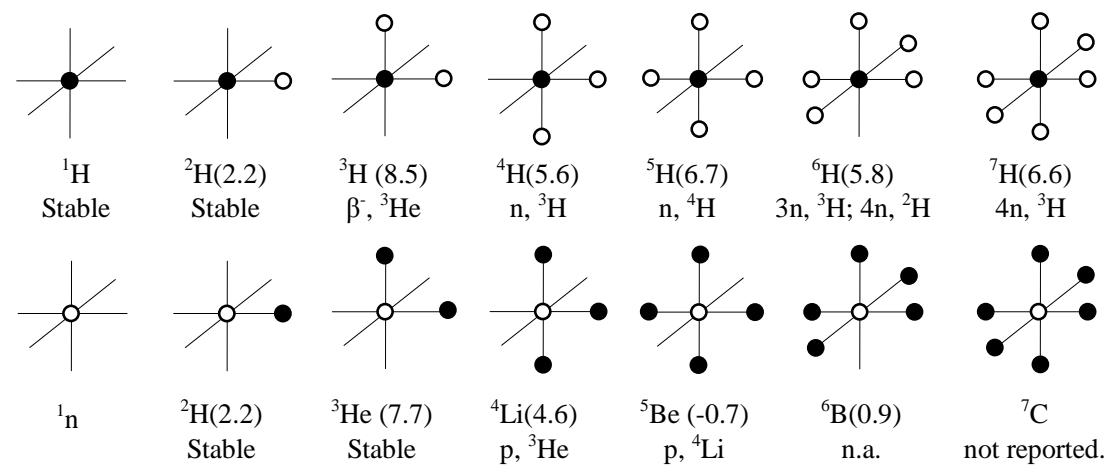

(a)
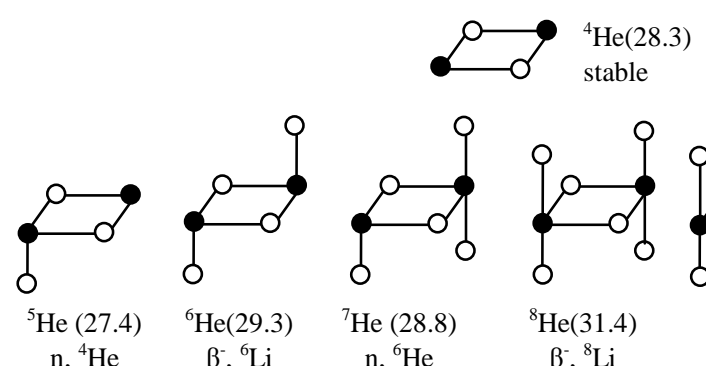

${ }^{6} \mathrm{He}(29.3)$

$\beta,{ }^{6} \mathrm{Li}$
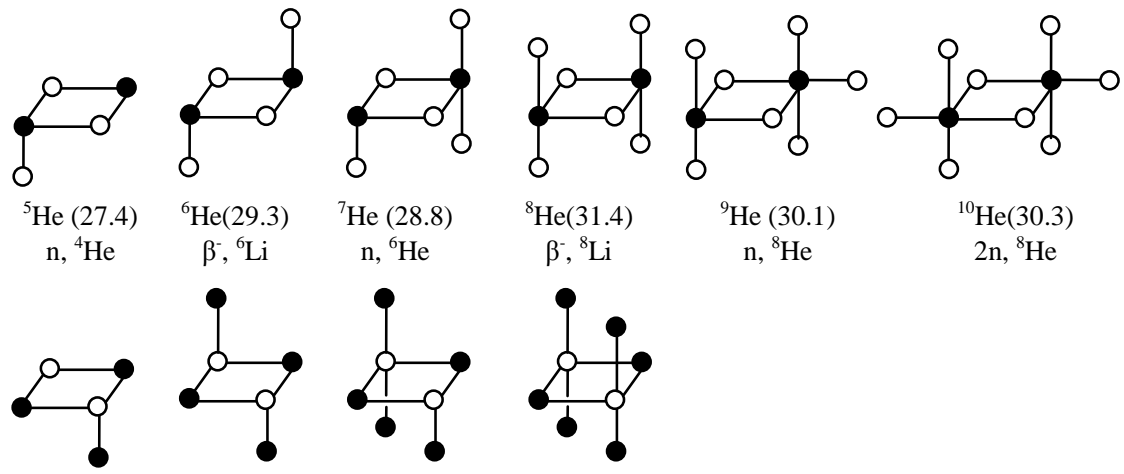

$2 \mathrm{n},{ }^{8} \mathrm{He}$

${ }^{5} \operatorname{Li}(26.3)$

${ }^{6} \mathrm{Be}(26.9)$

${ }^{7} \mathrm{~B}(24.7)$

${ }^{8} \mathrm{C}(24.8)$

p, ${ }^{4} \mathrm{He}$

2p, ${ }^{4} \mathrm{He}$

$\mathrm{p},{ }^{6} \mathrm{Be}$

$2 \mathrm{p},{ }^{6} \mathrm{Be}$

(b)

Figure 1. The possible shapes of (a) single-P nuclides (isotopes of $\mathrm{H}$ ) and single-N nuclides (from ${ }^{1} \mathrm{n}$ to ${ }^{7} \mathrm{C}$ ), (b) nuclides based on $\mathbf{P}_{2} \mathbf{N}_{2}$ ring. Black ball stands for $\mathbf{P}$ and white one for $\mathbf{N}$ (same in following figures). $E_{\mathrm{B}}$ (in $\mathrm{MeV}$, in parenthesis), main decay mode and the daughter isotope are marked beside each nuclide.

there are a few possibilities and more when $Z$ becomes large, a common feature is that the gravity centers of $\mathbf{P}$ and $\mathbf{N}$ are separated and are eccentric to the gravity center of nuclide. This can be easily proved mathematically. In addition, one can always find one or more arrangement with antisymmetric center, through which each $\mathbf{P}$ can find an $\mathbf{N}$ by space reflection and vice versa. We assume that the most possible odd- $Z$ ring structure is antisymmetric and the most densely packed. For ${ }^{7} \mathrm{Li}$ and other nuclei, the extra $\mathbf{N}$ may not likely bind to a ring $\mathbf{P}$ as an open $\mathbf{N}$ like unstable nuclides of $\mathbf{P}_{2} \mathbf{N}_{2}$ family. Instead, when 2 or more ring $\mathbf{P}$ 's are geometrically available to share an extra $\mathbf{N}$ with 90 "bond angles" and same $D_{\mathrm{PN}}$, the extra $\mathbf{N}$ tends to be stable. It seems this is the most likely way the extra $\mathbf{N}$ combines with the ring considering the geometric arrangement and indistinguishableness of $\mathbf{N}$ 's. Actually, among all stable nuclei, the ratio of $\mathbf{N} / \mathbf{P}$ is in the range of 1.00 to $1.54\left({ }^{208} \mathrm{~Pb}\right)$, that means ring $\mathbf{P}$ is able to stably bind a little more than 0.5 extra $\mathbf{N}$ (or 2 ring $\mathbf{P}$ 's share one extra $\mathbf{N}$ ) at maximum, while no extra $\mathbf{P}$ can stably bind to ring $\mathbf{N}$. This is the reason that, in the $\mathbf{P}_{2} \mathbf{N}_{2}$ family, all the nuclides with extra $\mathbf{P}$ or extra $\mathbf{N}$ are unstable because of the valence limitation of the square shaped ring. From the shape of the ring structure, one can predict the possibly heaviest and the lightest isotopes of the related elements. As an example, based on $\mathbf{P}_{3} \mathbf{N}_{3}$ ring, the possibly heaviest isotope of lithium is ${ }^{16} \mathrm{Li}$ and the possibly lightest isotope of aluminium is ${ }^{16} \mathrm{Al}$. For other elements, the possibly heaviest and lightest isotopes can also be predicted if the structure of related ring is known.

The possible packing structures of some light even- $Z$ rings and their stable isotopes are also shown in Figure 2. By contrast to odd- $Z$ rings, all the even- $Z$ rings possess a superimposed gravity center of $\mathbf{P}$ and $\mathbf{N}$, which was tested by hundreds of examples without any exception and is destined to be proved mathematically. In addition, 

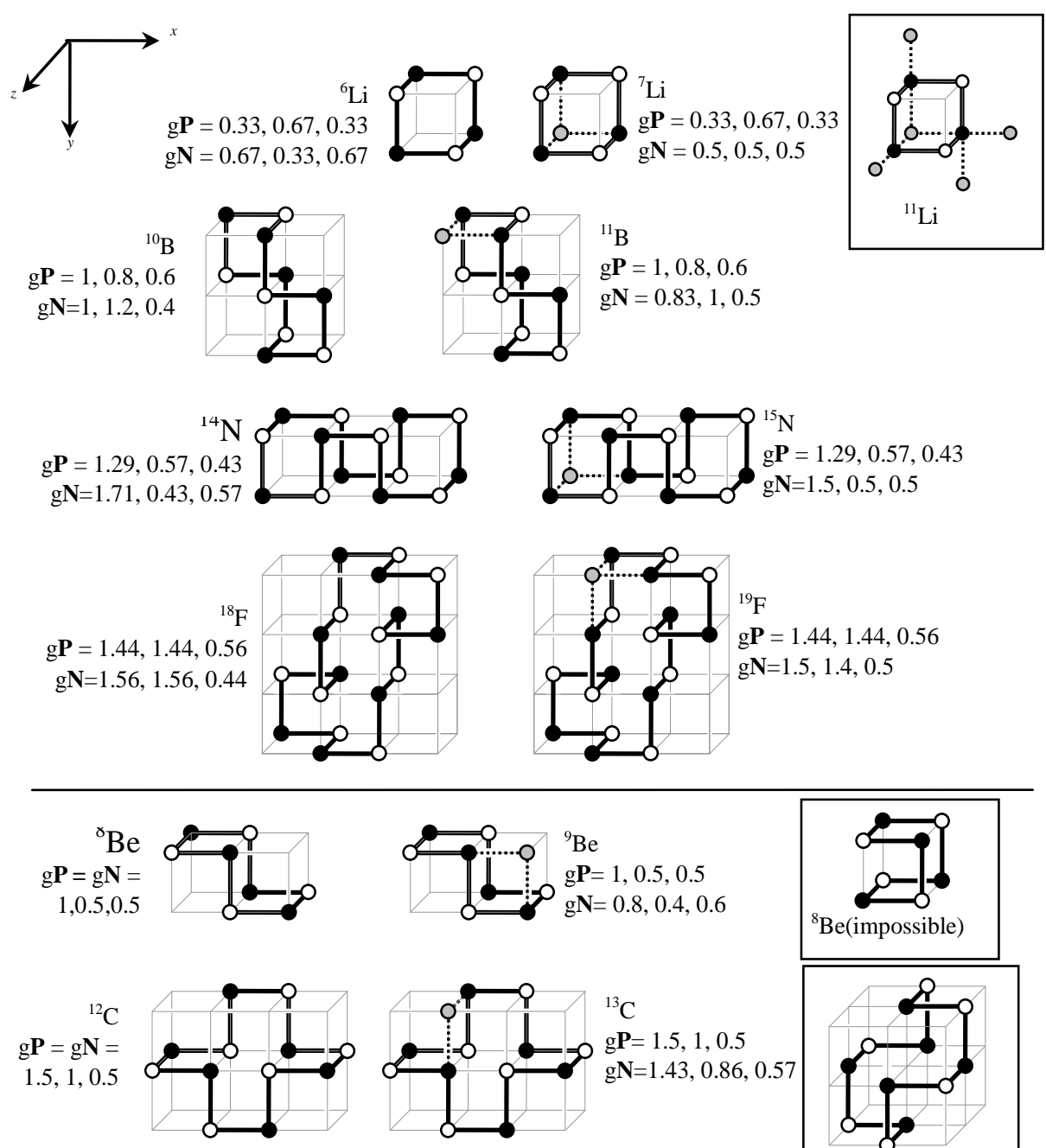

${ }^{13} \mathrm{C}$ $g \mathbf{P}=1.5,1,0.5$ $\mathrm{gN}=1.43,0.86,0.57$
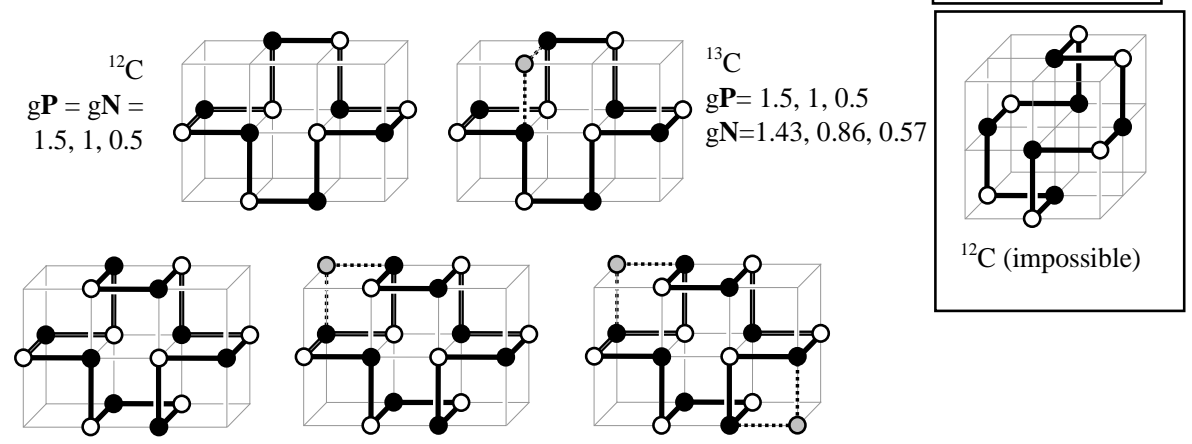

$$
\begin{aligned}
& { }^{16} \mathrm{O} \\
& \mathrm{g} \mathbf{P}=\mathrm{gN}= \\
& 1.5,1,0.5
\end{aligned}
$$

${ }^{17} \mathrm{O}$

$\mathrm{gP}=1.5,1,0.5$

$\mathrm{gN}=1.33,0.89,0.44$
${ }^{18} \mathrm{O}$
$\mathrm{gP}=\mathrm{gN}=$
$1.5,1,0.5$

Figure 2. The possible structures of some light nuclides based on "ring plus extra nucleon" model. For odd- $Z$ nuclides (above), the gravity centers of $\mathbf{P}$ and $\mathbf{N}$ ( $\mathrm{g} \mathbf{P}$ and gN) are eccentric and the rings are antisymmetrical. For even- $Z$ nuclides (below), $\mathbf{g P}$ and $\mathbf{g N}$ are superimposed, while the rings are center symmetrical and are indistinguishable when $\mathbf{P}$ and $\mathbf{N}$ interchange. The extra $\mathbf{N}$ is highlighted in gray and bond in dot-line. ${ }^{8} \mathrm{Be}$ in frame is impossible because it is non center symmetrical and geometrically unavailable for any stable extra $\mathbf{N}$.

some of the structures are center-symmetrical. We assume that the most possible ring structure of even- $Z$ nuclei is the most densely packed one with center-symmetry and is indistinguishable when all $\mathbf{P}$ and $\mathbf{N}$ interchange. In Figure 2, the framed ${ }^{12} \mathrm{C}$ is marked "impossible" because it mutates to another structure when $\mathbf{P}$ and $\mathbf{N}$ interchange. It is interesting to find that ${ }^{8} \mathrm{Be}$ is composed of two $\mathbf{P}_{2} \mathbf{N}_{2}$ squares and is ready to yield into two $\alpha$-particles. Only ${ }^{9} \mathrm{Be}$, with an extra $\mathbf{N}$ that bridges two squares by the manner mentioned above, is stable. Therefore, as another restriction, the most possible ring structure should avoid the arrangement that can split into 
two normal rings.

Because of the symmetrical and geometrical restrictions of ring structure, empty open space in a large nucleus $(Z>20)$ is unavoidable. An important function of extra $\mathbf{N}$ is to fill the open space, making the nuclide packed more densely and establishing adequate non-bond interaction. Figure 3 shows the nuclide size, characterized by radius of gyration, $\left[R^{2}\right]^{0.5}$ (as defined in the following equation) versus the nucleon number $A$. The points of stable nuclides locate around the line of slope $=1 / 3$, or the nuclide volume is roughly proportional to $A$. In addition, one can find a general trend that, for rings, the radius expands related to the line with $Z$ increases due to the open space $\left({ }^{16} \mathrm{O}\right.$ is special possibly because of double magic numbers, which will be revealed in future).

From the possible structures shown in Figure 2, one can figure out that if nuclei possess too many N's to be bind properly by 2 or more ring $\mathbf{P}$ 's, some open $\mathbf{N}$ will be unavoidable as a neutron halo and the nucleus will be unusually large, such as ${ }^{11} \mathrm{Li}$ in Figure 2. This is qualitatively accordant with the scattering cross-section observations for extremely $\mathbf{N}$-rich nuclides [6].

\section{Binding Energy per Nucleon}

The $E_{\mathrm{B}} / A$ for all the $\mathbf{P}_{X} \mathbf{N}_{x}$ rings, in Figure 4, display a zigzag feature, where even- $Z$ rings are at the vertex and odd- $Z$ rings at the nadir. As mentioned earlier, the fundamental difference for even- $Z$ and odd- $Z$ ring is that the former has superimposed gravity centers of $\mathbf{P}$ and $\mathbf{N}$, while the later is eccentric. It is obvious that eccentricity results in lower $E_{\mathrm{B}}$, which is possibly because the eccentric nucleus inside an atom requires more energy to spin faster to avoid the surrounding electrons to "feel" uneven.

It is well known that $E_{\mathrm{B}} / A$ of the isotopes of an element displays a specific zigzag feature, where the vertex always relates odd $A$ for odd- $Z$ elements, and relates even $A$ for even- $Z$ elements, as shown in the examples ( ${ }_{26} F e$ and ${ }_{29} \mathrm{Cu}$ ) in Figure 4. Weizasäcker's semi-empirical mass formula treated this feature by a selective function, $\mathrm{f}_{5}$ in an ad hoc way [2].

In this work, the degree of eccentricity, $S_{\mathrm{g}}$, is defined as the separation of the gravity centers of $\mathbf{P}$ and $\mathbf{N}$, $D_{g(P N)}$, over 2 times the radius of gyration, $\left[R^{2}\right]^{0.5}$,

$$
S_{g}=\frac{D_{g(\mathrm{PN})}}{2\left[R^{2}\right]^{0.5}}=\frac{D_{g(\mathrm{PN})}}{2 \sqrt{\frac{1}{A} \sum_{i=1}^{A} D_{i}^{2}}}
$$

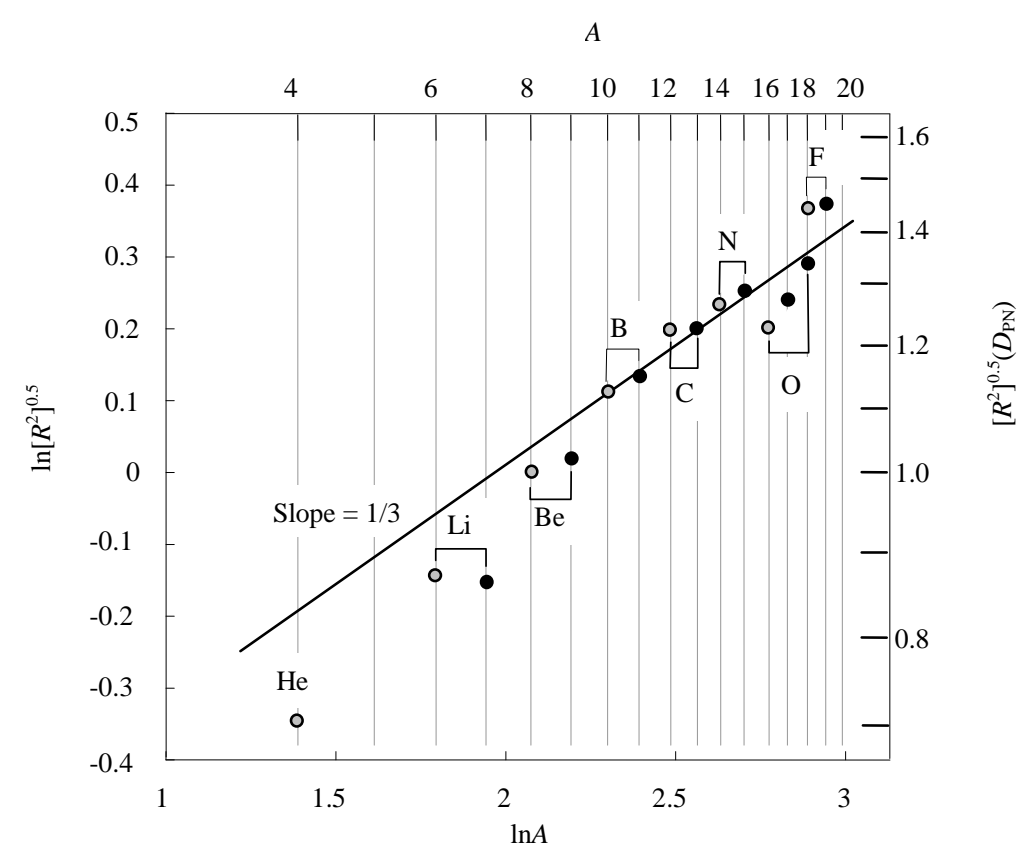

Figure 3. Radius of gyration vs $A$ for rings (in light gray) and their stable isotopes (in black) of some light nuclei $(Z=2$ to 9$)$. 


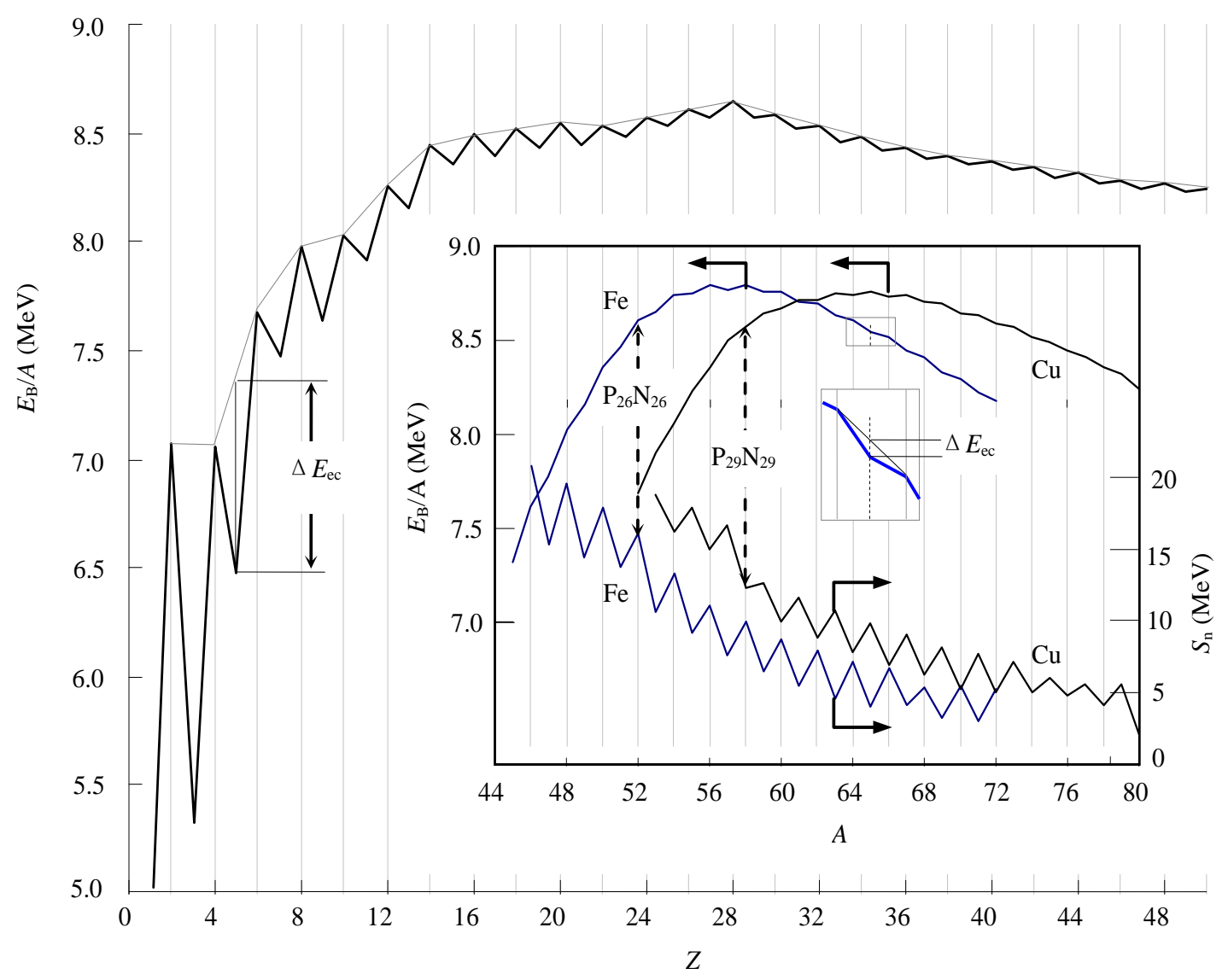

Figure 4. $E_{\mathrm{B}} / A$ of ring nuclides $\mathbf{P}_{Z} \mathbf{N}_{Z}$. The zigzag feature implies a fundamental difference between odd- and even- $Z$ rings. The envelope line for even- $Z$ ring is shown, with which the depression energy by eccentricity, $\Delta E_{\mathrm{ec}}$, for odd- $Z$ ring is defined. Embededis zigzag feature of $E_{\mathrm{B}} / A$ (above) and $S_{\mathrm{n}}$ (below) for even- $Z$ elements (26 $\mathrm{Fe}$ as an example) and odd- $Z$ elements $\left({ }_{29} \mathrm{Cu}\right.$ as an example). $\Delta E_{\mathrm{ec}}$ for $\mathbf{P}_{\mathrm{Z}} \mathbf{N}_{\mathrm{Z}+1}$ (even-Z) is defined.

where $D_{\mathrm{i}}$ is the length from $i$ 'th nucleon to the gravity center of the nucleus. For any even- $Z$ ring, $S_{\mathrm{g}}$ is always zero because $D_{g(\mathbf{P N})}=0$; while for odd- $Z$ rings, $S_{\mathrm{g}}$ is higher than 0 . From the definition, deuterium, ${ }^{2} \mathrm{H}$, has the highest $S_{\mathrm{g}}$ of 1 . For other light odd- $Z$ rings, such as ${ }^{6} \mathrm{Li}$ and ${ }^{10} \mathrm{~B}, S_{\mathrm{g}}$ is also quite high, and therefore leads up to a very low $E_{\mathrm{B}}$. The depression of $E_{\mathrm{B}} / A$ by eccentricity, $\Delta E_{\mathrm{ec}}$, is defined in Figure 4 for some simple odd- $Z$ rings and even-odd nuclides. The relationship between $S_{\mathrm{g}}$ and $\Delta E_{\mathrm{ec}}$ is demonstrated in Figure 5. It should be noted that this relationship is not very quantitative because $\Delta E_{\text {ec }}$ is also affected by non-bond interactions of a particular nuclide as will be mentioned later.

Cohesive interactions between metallic atoms are mostly governed by their electron configuration. Since the high $S_{\mathrm{g}}$ means the high nuclear "polarity", which provides an extra interaction between isolated atoms, like polar molecules have higher intermolecular interactions than nonpolar ones. That can explain $\mathrm{Li}$, Be and B respectively demonstrate the unusually highest melting point and boiling point in their group (similar electron configuration) of periodic table.

To understand the zigzag feature, Figure 6 depicts the $D_{\mathrm{g}(\mathbf{P N})}$ and eccentricity $S_{\mathrm{g}}$ shift caused by extra nucleon in different cases, that results in fluctuation of $E_{\mathrm{B}} / A$ exactly as the way as the rings or isotopes of any element do (vertex for even $Z$ at even $A$ while odd $Z$ at odd $A$ ).

The envelope line of $E_{\mathrm{B}} / A$ for even- $Z$ rings in Figure 4 demonstrates that, without the energy depression by eccentricity, $E_{\mathrm{B}} / A$ increases from very low for light $Z$ ring to maximum at $\mathbf{P}_{28} \mathbf{N}_{28}$, and then decreases slowly. This should be due to the variation of non-bond interaction.

For most elements, $E_{\mathrm{B}} / A$ of a ring, as basic structure, is not the highest among the isotopes, as the examples shown in Figure 4. It is because extra $\mathbf{N}$, which fills the open spaces in large ring and builds adequate non-bond interaction, may lead to higher $E_{\mathrm{B}} / A$ and stability. Nevertheless, special stability of ring structure can be detected 


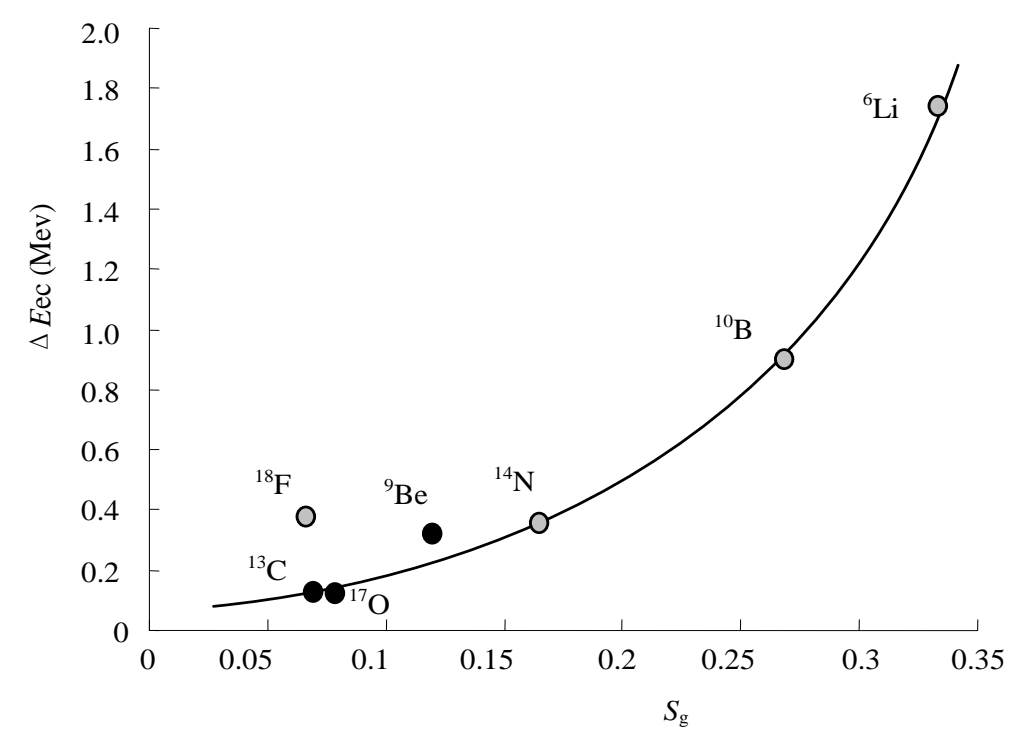

Figure 5. Relationship between degree of eccentricity, $S_{\mathrm{g}}$, and depression energy by eccentricity, $\Delta E_{\mathrm{ec}}$, for eccentric nuclides. The $\Delta E_{\mathrm{ec}}$ of odd- $Z$ ring (in light gray) and even- $Z$ nuclide $\mathbf{P}_{Z} \mathbf{N}_{Z+1}$ (in black) are defined in Figure 4.

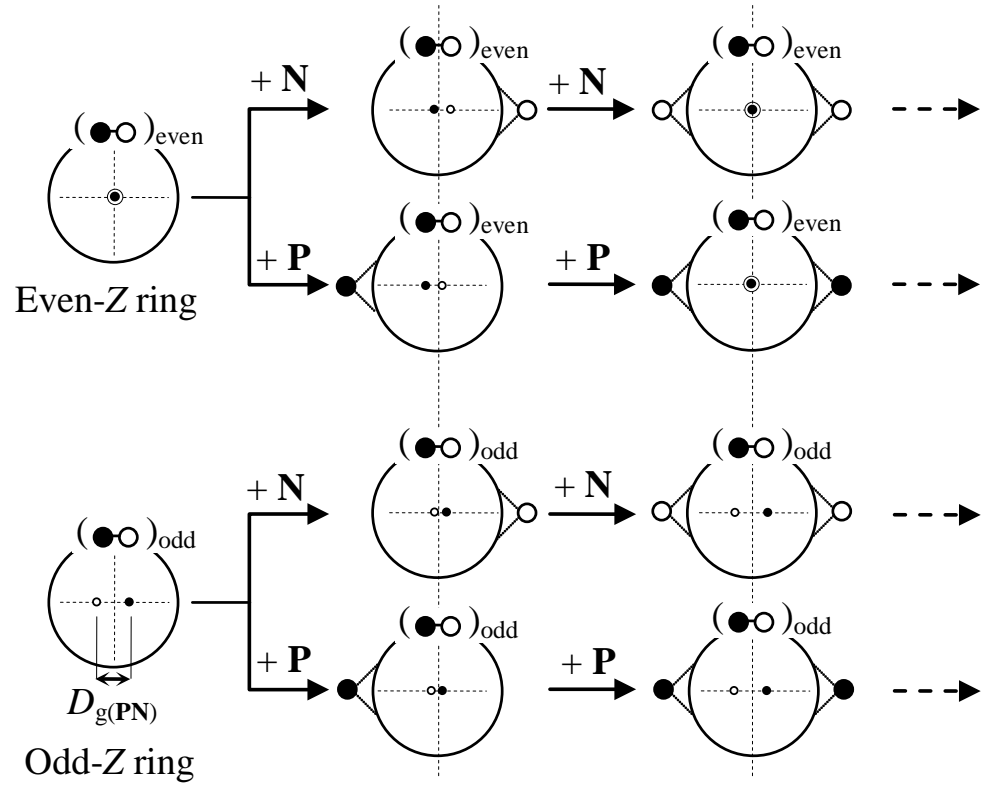

Figure 6. The explanation of $E_{\mathrm{B}} / A$ zigzag feature of nuclei. Even- $Z$ ring has superimposed gravity centers of $\mathbf{P}$ (tiny black dot) and $\mathbf{N}$ (tiny white dot); while odd- $Z$ ring has eccentric gravity centers. Extra $\mathbf{N}$ or $\mathbf{P}$ shifts the gravity centers and therefore $D_{\mathrm{g}(\mathbf{P N})}$ as well as $\Delta E_{\mathrm{ec}}$ fluctuates.

in many facts. Weizasäcker formula includes a symmetry term $\mathrm{f}_{4}$ emphasizing $\mathbf{P}_{Z} \mathbf{N}_{Z}$ is more favored in energy [2]. This can also be shown in Figure 4 that, except $\mathbf{P}$-rich nuclides, $\mathbf{P}_{Z} \mathbf{N}_{Z}$ always possesses the highest one-N separation energy, $S_{n}$ (for most odd- $Z$ nuclei the highest is $\mathbf{P}_{Z} \mathbf{N}_{Z+1}$ because of lower eccentricity). That is to say, $\mathbf{N}$ in a ring structure is generally more stable than extra $\mathbf{N}$. Since extra $\mathbf{P}$ is much more unstable, the normal extra nucleons can only be $\mathbf{N}$ or $\mathbf{P}$, excluding $\mathbf{N}$ and $\mathbf{P}$.

Basically, $E_{\mathrm{B}} / A$ of a nucleus is governed by many factors. Strong force between binding $\mathbf{P}$ and $\mathbf{N}$ in a ring plays the most important role, up to about $7 \mathrm{MeV}$ (as in ${ }^{4} \mathrm{He}$ ), which should be equal for all rings. The weak force acts between non-bond nucleons (P..N, N..N and P..P) in a ring that provides higher $E_{\mathrm{B}} / A$ up to $8.5 \mathrm{MeV}$ 
(as in ${ }^{40} \mathrm{Ca}$ ). The open spaces hinders non-bond interaction, and makes nuclide very unstable even $E_{\mathrm{B}} / A$ is not so low. The extra $\mathbf{N}$ shared by 2 or more ring $\mathbf{P}$ 's, which contributes similar strong force, provides more weak force and, therefore, can increase $E_{\mathrm{B}} / A$ up to $8.8 \mathrm{MeV}$ (as in ${ }^{62} \mathrm{Ni}$ ). When ring is too large, the open spaces may not be completely filled by extra $\mathbf{N}$, and $E_{\mathrm{B}} / A$ lowers gradually. Eccentricity is an important factor that decreases $E_{\mathrm{B}}$ especially for light nuclei as depicted in Figure 5. In addition, excess extra $\mathbf{N}$ or $\mathbf{P}$ can only connect to the ring as open nucleons, which have very little or minus contribution to strong force and thus result in many very unstable nuclei with very low $E_{\mathrm{B}} / A$. Because of the complicated effects, the nuclide shapes shown in Figure 2 are only the most possible arrangements and need to be confirmed or revised by new theory considering more details of nuclear forces and new experimental observations.

\section{Mirror Nuclei}

Mirror nuclei are the pair of nuclides $\mathbf{P}_{X+n} \mathbf{N}_{X}$ and $\mathbf{P}_{X} \mathbf{N}_{X+n}$. Some correlations of the pair have been reported since long ago [7]-[10]. The most remarkable fact is the identical spin and parity, $J^{\pi}$, of mirror nuclei in ground state as summarized in Table 1, with very few exceptions or uncertainties. Since the ring is indistinguishable when $\mathbf{P}$ and $\mathbf{N}$ interchange, any nuclide with $n$ extra $\mathbf{N}($ 's) will have a counterpart with $n$ extra $\mathbf{P}($ 's) in similar way of binding to the ring. Thus, the shapes of the pair nuclides are similar but $\mathbf{P}$ and $\mathbf{N}$ interchange, just like a black-white photo and the negative film. This should be the basic reason for the following equation.

$$
J^{\pi}\left(\mathbf{P}_{X \pm n} \mathbf{N}_{X}\right)=J^{\pi}\left(\mathbf{P}_{X} \mathbf{N}_{X \pm n}\right)
$$

It is also reasonable to predict the identity of degree of eccentricity for the pair.

$$
S_{g}\left(\mathbf{P}_{X \pm n} \mathbf{N}_{X}\right)=S_{g}\left(\mathbf{P}_{X} \mathbf{N}_{X \pm n}\right)
$$

${ }^{7} \mathrm{Be}$ is present in the atmosphere in trace amount [11] as the only natural occurring radioisotope with the ratio of $\mathbf{N} / \mathbf{P}<1$. As the mirror nuclide of ${ }^{7} \mathrm{Li}$, ${ }^{7} \mathrm{Be}$ has an extra $\mathbf{P}$ and can also obtain a large energy bonus from the highest eccentricity in ${ }^{6} \mathrm{Li}$ although, as expectation, ${ }^{7} \mathrm{Be}$ is still not stable enough as ${ }^{7} \mathrm{Li}$.

Figure 7 demonstrates the $E_{\mathrm{B}} / A$ of mirror nuclei. It is clear that the $E_{\mathrm{B}} / A$ of $\mathbf{P}_{X} \mathbf{N}_{X+n}$ is always larger than that of $\mathbf{P}_{X+n} \mathbf{N}_{X}$. Compared with the zigzag feature of ring $\mathbf{P}_{X} \mathbf{N}_{X}$ mentioned earlier, when $n$ is odd, the curves are smooth because odd extra $\mathbf{P}$ or $\mathbf{N}$ diminishes the depression energy by eccentricity for odd- $X$ nuclides. Of course, when $n$ is even, the curves zigzag again. In addition, it is notable that the difference of $E_{\mathrm{B}} / A$ for any pair is nearly a constant: averagely $0.179,0.368,0.559,0.763,0.926$ and $1.084 \mathrm{MeV}$ for $n=1,2,3,4,5$ and 6 respectively (the curves for $n=5$ and 6 are omitted in Figure 7). This can be described with following equation.

$$
E_{B} / A\left(\mathbf{P}_{X} \mathbf{N}_{X+n}\right)-E_{B} / A\left(\mathbf{P}_{X+n} \mathbf{N}_{X}\right) \approx 0.184 n(\mathrm{MeV})
$$

In summary, the ring plus extra nucleon model seems properly meet the structure requirement to the correlations of mirror nuclei.

\section{Conclusion}

A nucleus $\mathbf{P}_{X} \mathbf{N}_{Y}(X, Y \geq 2)$ is composed of a ring $\mathbf{P}_{X} \mathbf{N}_{X}$ with $\mathbf{P}$ and $\mathbf{N}$ alternative binding plus $Y-X$ extra $\mathbf{N}($ 's) if $Y>X$, or a ring $\mathbf{P}_{Y} \mathbf{N}_{Y}$ plus $X-Y$ extra $\mathbf{P}\left(\right.$ 's) if $X>Y$. The ring folds with a "bond angle" of $90^{\circ}$ for every 3 continuous nucleons. Extra $\mathbf{N}$ can bound to ring-P with the same "bond angle" and "bond distance". Extra $\mathbf{P}$ can bound to ring $\mathbf{N}$ in a similar way but the binding is weaker than that of extra $\mathbf{P}$. When 2 or more ring $\mathbf{P}$ 's are geometrically available, the extra $\mathbf{N}$ tends to be stable. Excess extra $\mathbf{N}$ results in open $\mathbf{N}$ with low $E_{\mathrm{B}} / A$ and neutron halo with large radius. Even- $Z$ rings, as well as normal even-even nuclei, always have superimposed gravity centers of $\mathbf{P}$ and $\mathbf{N}$; while for odd- $Z$ rings, as well as odd- $A$ nuclides, both centers of $\mathbf{P}$ and $\mathbf{N}$ must be eccentric. The eccentricity results in a depression of $E_{\mathrm{B}}$. Therefore, the zigzag features of $E_{\mathrm{B}} / A$ of an element differing for odd and even $Z$ can be simply explained by the shift of eccentricity by extra nucleons. Symmetry center may present in any even-even nuclei. While for odd- $Z$ rings, only antisymmetry center is possible. In both cases of even and odd- $Z$, the rings are indistinguishable when $\mathbf{P}$ and $\mathbf{N}$ interchange. Based on the ring plus extra nucleon model, the mirror nuclei are equivalent in structure and demonstrate identical spin and parity. As the eccentricity shift, the $E_{\mathrm{B}} / A$ curves of mirror nuclei display smooth when the number of extra nucleon $n$ is odd, and zigzag 
Table 1. The identical spin and parity for mirror nuclei: $J^{\pi}\left(\mathbf{P}_{X+n} \mathbf{N}_{X}\right)=J^{\pi}\left(\mathbf{P}_{X} \mathbf{N}_{X+n}\right)^{*}$.

\begin{tabular}{|c|c|c|c|c|c|c|c|c|c|c|c|c|c|}
\hline$X$ & $\mathbf{P}_{X+5} \mathbf{N}_{X}$ & $\mathbf{P}_{X+4} \mathbf{N}_{X}$ & & ${ }_{3} \mathbf{N}_{X}$ & $\mathbf{P}_{X+2} \mathbf{N}_{X}$ & $\mathbf{P}_{X+1} \mathbf{N}_{X}$ & $\mathbf{P}_{X} \mathbf{N}_{X}$ & $\mathbf{P}_{X} \mathbf{N}_{X+1}$ & $\mathbf{P}_{X} \mathbf{N}_{X+2}$ & $\mathbf{P}_{X} \mathbf{N}_{X+3}$ & $\mathbf{P}_{X} \mathbf{N}_{X+4}$ & & $\mathbf{P}_{X} \mathbf{N}_{X+5}$ \\
\hline 1 & & ${ }^{6} \mathrm{~B}$ & ${ }^{5} \mathrm{Be}$ & $1 / 2^{+}$ & ${ }^{4} \mathrm{Li} \quad 2^{-}$ & ${ }^{3} \mathrm{He} \quad 1 / 2^{+}$ & ${ }^{2} \mathrm{H} \mathrm{l}^{+}$ & ${ }^{3} \mathrm{H} \quad 1 / 2^{+}$ & ${ }^{4} \mathrm{H} \quad 2^{-}$ & $\begin{array}{ll}{ }^{5} \mathrm{H} & 1 / 2^{+}\end{array}$ & ${ }^{6} \mathrm{H} \quad 2^{-}$ & & \\
\hline 2 & & ${ }^{8} \mathrm{C} \quad 0^{+}$ & ${ }^{7} \mathrm{~B}$ & $3 / 2^{-}$ & ${ }^{6} \mathrm{Be} \quad 0^{+}$ & ${ }^{5} \mathrm{Li} \quad 3 / 2^{-}$ & ${ }^{4} \mathrm{He} 0^{+}$ & ${ }^{5} \mathrm{He} \quad 3 / 2^{-}$ & ${ }^{6} \mathrm{He} \quad 0^{+}$ & ${ }^{7} \mathrm{He} 3 / 2^{-}$ & ${ }^{8} \mathrm{He} \quad 0^{+}$ & & \\
\hline 3 & & ${ }^{10}{\mathrm{~N} 2^{-}}^{-}$ & ${ }^{9} \mathrm{C}$ & $3 / 2^{-}$ & ${ }^{8} \mathrm{~B} \quad 2^{+}$ & ${ }^{7} \mathrm{Be} \quad 3 / 2^{-}$ & ${ }^{6} \mathrm{Li} 1^{+}$ & ${ }^{7} \mathrm{Li} \quad 3 / 2^{-}$ & ${ }^{8} \mathrm{Li} \quad 2^{+}$ & ${ }^{9} \mathrm{Li} \quad 3 / 2^{-}$ & ${ }^{10} \mathrm{Li} 1^{-}, 2^{-}$ & & \\
\hline 4 & & ${ }^{12} \mathrm{O}^{+}$ & ${ }^{11} \mathrm{~N}$ & $1 / 2^{+}$ & ${ }^{10} \mathrm{C} \quad 0^{+}$ & ${ }^{9} \mathrm{~B} \quad 3 / 2^{-}$ & ${ }^{8} \mathrm{Be} 0^{+}$ & ${ }^{9} \mathrm{Be} \quad 3 / 2^{-}$ & ${ }^{10} \mathrm{Be} \quad 0^{+}$ & ${ }^{11} \mathrm{Be} 1 / 2^{+}$ & ${ }^{12} \mathrm{Be} \quad 0^{+}$ & & \\
\hline 5 & & ${ }^{14} \mathrm{~F} \quad 2^{-}$ & ${ }^{13} \mathrm{O}$ & $3 / 2^{-}$ & ${ }^{12} \mathrm{~N} \quad 1^{+}$ & ${ }^{11} \mathrm{C} \quad 3 / 2^{-}$ & ${ }^{10} \mathrm{~B} 3^{+}$ & ${ }^{11} \mathrm{~B} \quad 3 / 2^{-}$ & ${ }^{12} \mathrm{~B} \quad 1^{+}$ & ${ }^{13} \mathrm{~B} \quad 3 / 2^{-}$ & ${ }^{14} \mathrm{~B} \quad 2^{-}$ & & \\
\hline 6 & & ${ }^{16} \mathrm{Ne} 0^{+}$ & ${ }^{15} \mathrm{~F}$ & $1 / 2^{+}$ & ${ }^{14} \mathrm{O} \quad 0^{+}$ & ${ }^{13} \mathrm{~N} \quad 1 / 2^{-}$ & ${ }^{12} \mathrm{C}^{+}$ & ${ }^{13} \mathrm{C} \quad 1 / 2^{-}$ & ${ }^{14} \mathrm{C} \quad 0^{+}$ & ${ }^{15} \mathrm{C} \quad 1 / 2^{+}$ & ${ }^{16} \mathrm{C} \quad 0^{+}$ & & \\
\hline 7 & ${ }^{19} \mathrm{Mg} \quad 1 / 2^{-}$ & ${ }^{18} \mathrm{Na}$ & ${ }^{17} \mathrm{Ne}$ & $1 / 2^{-}$ & ${ }^{16} \mathrm{~F} \quad 0^{-} ?$ & ${ }^{15} \mathrm{O} \quad 1 / 2^{-}$ & ${ }^{14} \mathrm{~N}^{+}$ & ${ }^{15} \mathrm{~N} \quad 1 / 2^{-}$ & ${ }^{16} \mathrm{~N}^{-} ?$ & ${ }^{17} \mathrm{~N} 1 / 2^{-}$ & ${ }^{18} \mathrm{~N} \quad 1^{-}$ & ${ }^{19} \mathrm{~N}$ & $1 / 2^{-}$ \\
\hline 8 & ${ }^{21} \mathrm{Al} \quad 1 / 2^{+}$ & ${ }^{20} \mathrm{Mg} \mathrm{O}^{+}$ & ${ }^{19} \mathrm{Na}$ & $5 / 2^{+}$ & ${ }^{18} \mathrm{Ne} 0^{+}$ & ${ }^{17} \mathrm{~F} \quad 5 / 2^{+}$ & ${ }^{16} \mathrm{O} \quad 0^{+}$ & ${ }^{17} \mathrm{O} \quad 5 / 2^{+}$ & $\begin{array}{ll}{ }^{18} & 0^{+}\end{array}$ & ${ }^{19} \mathrm{O} 5 / 2^{+}$ & ${ }^{20} \mathrm{O} \quad 0^{+}$ & ${ }^{21} \mathrm{O}$ & $(1 / 2,3 / 2,5 / 2)^{+}$ \\
\hline 9 & ${ }^{23} \mathrm{Si} \quad 3 / 2^{+}$ & ${ }^{22}{\mathrm{Al} 3^{+}}^{+}$ & ${ }^{21} \mathrm{Mg}$ & $5 / 2,3 / 2^{+}$ & ${ }^{20} \mathrm{Na} 2^{+}$ & ${ }^{19} \mathrm{Ne} 1 / 2^{+}$ & ${ }^{18} \mathrm{~F} 1^{+}$ & ${ }^{19} \mathrm{~F} \quad 1 / 2^{+}$ & ${ }^{20} \mathrm{~F} \quad 2^{+}$ & ${ }^{21} \mathrm{~F} \quad 5 / 2^{+}$ & ${ }^{22} \mathrm{~F} \quad 4^{+}, 3^{+}$ & ${ }^{23} \mathrm{~F}$ & $(3 / 2,5 / 2)^{+}$ \\
\hline 10 & ${ }^{25} \mathrm{P} \quad 1 / 2^{+} ?$ & ${ }^{24} \mathrm{Si} 0^{+}$ & ${ }^{23} \mathrm{Al}$ & $5 / 2^{+}$ & ${ }^{22} \mathrm{Mg} 0^{+}$ & ${ }^{21} \mathrm{Na} 3 / 2^{+}$ & ${ }^{20} \mathrm{Ne} 0^{+}$ & ${ }^{21} \mathrm{Ne} \quad 3 / 2^{+}$ & ${ }^{22} \mathrm{Ne} 0^{+}$ & ${ }^{23} \mathrm{Ne} 5 / 2^{+}$ & ${ }^{24} \mathrm{Ne} \quad 0^{+}$ & ${ }^{25} \mathrm{Ne}$ & $3 / 2^{+} ?$ \\
\hline 11 & ${ }^{27} \mathrm{~S} \quad 5 / 2^{+}$ & ${ }^{26} \mathrm{P} \quad 3^{+}$ & ${ }^{25} \mathrm{Si}$ & $5 / 2^{+}$ & ${ }^{24} \mathrm{Al} \quad 4^{+}$ & ${ }^{23} \mathrm{Mg} \mathrm{3} / 2^{+}$ & ${ }^{22} \mathrm{Na} 3^{+}$ & ${ }^{23} \mathrm{Na} \quad 3 / 2^{+}$ & ${ }^{24} \mathrm{Na} 4^{+}$ & ${ }^{25} \mathrm{Na} 5 / 2^{+}$ & ${ }^{26} \mathrm{Na} \quad 3^{+}$ & ${ }^{27} \mathrm{Na}$ & $5 / 2^{+}$ \\
\hline 12 & ${ }^{29} \mathrm{Cl} \quad 3 / 2^{+}$ & ${ }^{28} \mathrm{SO}^{+}$ & ${ }^{27} \mathrm{P}$ & $1 / 2^{+}$ & ${ }^{26} \mathrm{Si} \quad 0^{+}$ & ${ }^{25} \mathrm{Al} \quad 5 / 2^{+}$ & ${ }^{24} \mathrm{Mg} 0^{+}$ & ${ }^{25} \mathrm{Mg} \mathrm{5} / 2^{+}$ & ${ }^{26} \mathrm{Mg} 0^{+}$ & ${ }^{27} \mathrm{Mg} 1 / 2^{+}$ & ${ }^{28} \mathrm{Mg} \quad 0^{+}$ & ${ }^{29} \mathrm{Mg}$ & $3 / 2^{+}$ \\
\hline 13 & ${ }^{31} \mathrm{Ar} \quad 5 / 2^{+}$ & ${ }^{30} \mathrm{Cl} 3^{+}$ & ${ }^{29} \mathrm{~S}$ & $5 / 2^{+}$ & ${ }^{28} \mathrm{P} \quad 3^{+}$ & ${ }^{27} \mathrm{Si} \quad 5 / 2^{+}$ & ${ }^{26} \mathrm{Al} \mathrm{5}$ & ${ }^{27} \mathrm{Al} \quad 5 / 2^{+}$ & ${ }^{28} \mathrm{Al} \quad 3^{+}$ & ${ }^{29} \mathrm{Al} 5 / 2^{+}$ & ${ }^{30} \mathrm{Al} \quad 3^{+}$ & ${ }^{31} \mathrm{Al}$ & $(3 / 2,5 / 2)^{+}$ \\
\hline 14 & ${ }^{33} \mathrm{~K} \quad 3 / 2^{+}$ & ${ }^{32} \mathrm{Ar} 0^{+}$ & ${ }^{31} \mathrm{Cl}$ & $3 / 2^{+}$ & ${ }^{30} \mathrm{~S} \quad 0^{+}$ & ${ }^{29} \mathrm{P} \quad 1 / 2^{+}$ & ${ }^{28} \mathrm{Si} 0^{+}$ & ${ }^{29} \mathrm{Si} \quad 1 / 2^{+}$ & ${ }^{30} \mathrm{Si} \quad 0^{+}$ & ${ }^{31} \mathrm{Si} 3 / 2^{+}$ & ${ }^{32} \mathrm{Si} \quad 0^{+}$ & ${ }^{33} \mathrm{Si}$ & $3 / 2^{+}$ \\
\hline 15 & ${ }^{35} \mathrm{Ca} \quad 1 / 2^{+}$ & ${ }^{34} \mathrm{~K} \quad 1^{+}$ & ${ }^{33} \mathrm{Ar}$ & $1 / 2^{+}$ & ${ }^{32} \mathrm{Cl} 1^{+}$ & ${ }^{31} \mathrm{~S} \quad 1 / 2^{+}$ & ${ }^{30} \mathrm{P} 1^{+}$ & ${ }^{31} \mathrm{P} \quad 1 / 2^{+}$ & ${ }^{32} \mathrm{P} \quad 1^{+}$ & ${ }^{33} \mathrm{P} \quad 1 / 2^{+}$ & ${ }^{34} \mathrm{P} \quad 1^{+}$ & ${ }^{35} \mathrm{P}$ & $1 / 2^{+}$ \\
\hline 16 & ${ }^{37}$ Sc $\quad 7 / 2^{-}$ & ${ }^{36} \mathrm{Ca} 0^{+}$ & ${ }^{35} \mathrm{~K}$ & $3 / 2^{+}$ & ${ }^{34} \mathrm{Ar} \quad 0^{+}$ & ${ }^{33} \mathrm{Cl} \quad 3 / 2^{+}$ & ${ }^{32} \mathrm{~S} \quad 0^{+}$ & ${ }^{33} \mathrm{~S} \quad 3 / 2^{+}$ & ${ }^{34} \mathrm{~S} \quad 0^{+}$ & ${ }^{35} \mathrm{~S} \quad 3 / 2^{+}$ & ${ }^{36} \mathrm{~S} \quad 0^{+}$ & ${ }^{37} \mathrm{~S}$ & $7 / 2^{-}$ \\
\hline 17 & ${ }^{39} \mathrm{Ti} \quad 3 / 2^{+}$ & ${ }^{38} \mathrm{Sc} 2^{-}$ & ${ }^{37} \mathrm{Ca}$ & $3 / 2^{+}$ & ${ }^{36} \mathrm{~K} \quad 2^{+}$ & ${ }^{35} \mathrm{Ar} \quad 3 / 2^{+}$ & ${ }^{34} \mathrm{Cl} 0^{+}$ & ${ }^{35} \mathrm{Cl} \quad 3 / 2^{+}$ & ${ }^{36} \mathrm{Cl} \quad 2^{+}$ & ${ }^{37} \mathrm{Cl} 3 / 2^{+}$ & ${ }^{38} \mathrm{Cl} \quad 2^{-}$ & ${ }^{39} \mathrm{Cl}$ & $3 / 2^{+}$ \\
\hline 18 & ${ }^{41} \mathrm{~V} \quad 7 / 2^{-}$ & ${ }^{40} \mathrm{Ti} 0^{+}$ & ${ }^{39} \mathrm{Sc}$ & $7 / 2^{-}$ & ${ }^{38} \mathrm{Ca} \quad 0^{+}$ & ${ }^{37} \mathrm{~K} \quad 3 / 2^{+}$ & ${ }^{36} \mathrm{Ar} 0^{+}$ & ${ }^{37} \mathrm{Ar} \quad 3 / 2^{+}$ & ${ }^{38} \mathrm{Ar} \quad 0^{+}$ & ${ }^{39} \mathrm{Ar} 7 / 2^{-}$ & ${ }^{40} \mathrm{Ar} \quad 0^{+}$ & ${ }^{41} \mathrm{Ar}$ & $7 / 2^{-}$ \\
\hline 19 & ${ }^{43} \mathrm{Cr} \quad 3 / 2^{+}$ & ${ }^{42} \mathrm{~V}^{-}$ & ${ }^{41} \mathrm{Ti}$ & $3 / 2^{+}$ & ${ }^{40} \mathrm{Sc} \quad 4^{-}$ & ${ }^{39} \mathrm{Ca} \quad 3 / 2^{+}$ & 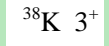 & ${ }^{39} \mathrm{~K} \quad 3 / 2^{+}$ & ${ }^{40} \mathrm{~K} \quad 4^{-}$ & ${ }^{41} \mathrm{~K} \quad 3 / 2^{+}$ & ${ }^{42} \mathrm{~K} \quad 2^{-}$ & ${ }^{43} \mathrm{~K}$ & $3 / 2^{+}$ \\
\hline 20 & ${ }^{45} \mathrm{Mn} \quad 7 / 2^{-}$ & ${ }^{44} \mathrm{Cr} 0^{+}$ & ${ }^{43} \mathrm{~V}$ & $7 / 2^{-}$ & ${ }^{42} \mathrm{Ti} \quad 0^{+}$ & ${ }^{41} \mathrm{Sc} \quad 7 / 2^{-}$ & ${ }^{40} \mathrm{Ca} 0^{+}$ & ${ }^{41} \mathrm{Ca} \quad 7 / 2^{-}$ & ${ }^{42} \mathrm{Ca} 0^{+}$ & ${ }^{43} \mathrm{Ca} 7 / 2^{-}$ & ${ }^{44} \mathrm{Ca} \quad 0^{+}$ & ${ }^{45} \mathrm{Ca}$ & $7 / 2^{-}$ \\
\hline 21 & ${ }^{47} \mathrm{Fe} \quad 7 / 2^{-}$ & ${ }^{46} \mathrm{Mn} 4^{+}$ & ${ }^{45} \mathrm{Cr}$ & $7 / 2^{-}$ & ${ }^{44} \mathrm{~V} \quad 2^{+}$ & ${ }^{43} \mathrm{Ti} \quad 7 / 2^{-}$ & ${ }^{42}$ Sc $0^{+}$ & ${ }^{43}$ Sc $\quad 7 / 2^{-}$ & ${ }^{44} \mathrm{Sc} \quad 2^{+}$ & ${ }^{45} \mathrm{Sc} 7 / 2^{-}$ & ${ }^{46} \mathrm{Sc} \quad 4^{+}$ & ${ }^{47} \mathrm{Sc}$ & $7 / 2^{-}$ \\
\hline 22 & ${ }^{49} \mathrm{Co} \quad 7 / 2^{-}$ & ${ }^{48} \mathrm{Fe} 0^{+}$ & ${ }^{47} \mathrm{Mn}$ & $5 / 2^{-}$ & ${ }^{46} \mathrm{Cr} \quad 0^{+}$ & ${ }^{45} \mathrm{~V} \quad 7 / 2^{-}$ & ${ }^{44} \mathrm{Ti} 0^{+}$ & ${ }^{45} \mathrm{Ti} \quad 7 / 2^{-}$ & ${ }^{46} \mathrm{Ti} \quad 0^{+}$ & ${ }^{47} \mathrm{Ti} \quad 5 / 2^{-}$ & ${ }^{48} \mathrm{Ti} \quad 0^{+}$ & ${ }^{49} \mathrm{Ti}$ & $7 / 2^{-}$ \\
\hline 23 & ${ }^{51} \mathrm{Ni} \quad 7 / 2^{-}$ & ${ }^{50} \mathrm{Co}^{+}{ }^{+}$ & ${ }^{49} \mathrm{Fe}$ & $7 / 2^{-}$ & ${ }^{48} \mathrm{Mn} 4^{+}$ & ${ }^{47} \mathrm{Cr} \quad 3 / 2^{-}$ & ${ }^{46} \mathrm{~V}^{+}$ & ${ }^{47} \mathrm{~V} \quad 3 / 2^{-}$ & ${ }^{48} \mathrm{~V} \quad 4^{+}$ & ${ }^{49} \mathrm{~V}^{7 / 2^{-}}$ & ${ }^{50} \mathrm{~V} \quad 6^{+}$ & ${ }^{51} \mathrm{~V}$ & $7 / 2^{-}$ \\
\hline 24 & ${ }^{53} \mathrm{Cu} \quad 3 / 2^{-}$ & ${ }^{52} \mathrm{Ni} 0^{+}$ & ${ }^{51} \mathrm{Co}$ & $7 / 2^{-}$ & ${ }^{50} \mathrm{Fe} \quad 0^{+}$ & ${ }^{49} \mathrm{Mn} 5 / 2^{-}$ & ${ }^{48} \mathrm{Cr} 0^{+}$ & ${ }^{49} \mathrm{Cr} \quad 5 / 2^{-}$ & ${ }^{50} \mathrm{Cr} \quad 0^{+}$ & ${ }^{51} \mathrm{Cr} 7 / 2^{-}$ & ${ }^{52} \mathrm{Cr} \quad 0^{+}$ & ${ }^{53} \mathrm{Cr}$ & $3 / 2^{-}$ \\
\hline 25 & ${ }^{55} \mathrm{Zn} \quad 5 / 2^{-}$ & ${ }^{54} \mathrm{Cu} \mathrm{3}^{+}$ & ${ }^{53} \mathrm{Ni}$ & $7 / 2^{-}$ & ${ }^{52} \mathrm{Co} \quad 6^{+}$ & ${ }^{51} \mathrm{Fe} \quad 5 / 2^{-}$ & ${ }^{50} \mathrm{Mn} 0^{+}$ & ${ }^{51} \mathrm{Mn} 5 / 2^{-}$ & ${ }^{52} \mathrm{Mn} 6^{+}$ & ${ }^{53} \mathrm{Mn} 7 / 2^{-}$ & ${ }^{54} \mathrm{Mn} \quad 3^{+}$ & ${ }^{55} \mathrm{Mn}$ & $5 / 2^{-}$ \\
\hline 26 & ${ }^{57} \mathrm{Ga} \quad 1 / 2^{-}$ & ${ }^{56} \mathrm{Zn} 0^{+}$ & ${ }^{55} \mathrm{Cu}$ & $3 / 2^{-}$ & ${ }^{54} \mathrm{Ni} \quad 0^{+}$ & ${ }^{53} \mathrm{Co} \quad 7 / 2^{-}$ & ${ }^{52} \mathrm{Fe} 0^{+}$ & ${ }^{53} \mathrm{Fe} \quad 7 / 2^{-}$ & ${ }^{54} \mathrm{Fe} \quad 0^{+}$ & ${ }^{55} \mathrm{Fe} \quad 3 / 2^{-}$ & ${ }^{56} \mathrm{Fe} \quad 0^{+}$ & ${ }^{57} \mathrm{Fe}$ & $1 / 2^{-}$ \\
\hline 27 & ${ }^{59} \mathrm{Ce} \quad 7 / 2^{-}$ & ${ }^{58} \mathrm{Ga} 2^{+}$ & ${ }^{57} \mathrm{Zn}$ & $7 / 2^{-}$ & ${ }^{56} \mathrm{Cu} 4^{+}$ & ${ }^{55} \mathrm{Ni} \quad 7 / 2^{-}$ & ${ }^{54} \mathrm{Co} 0^{+}$ & ${ }^{55} \mathrm{Co} \quad 7 / 2^{-}$ & ${ }^{56} \mathrm{Co} 4^{+}$ & ${ }^{57} \mathrm{Co} 7 / 2^{-}$ & ${ }^{58} \mathrm{Co} \quad 2^{+}$ & ${ }^{59} \mathrm{Co}$ & $7 / 2^{-}$ \\
\hline 28 & ${ }^{61}$ As $\quad 3 / 2^{-}$ & ${ }^{60} \mathrm{Ge} 0^{+}$ & ${ }^{59} \mathrm{Ga}$ & $3 / 2^{-}$ & ${ }^{58} \mathrm{Zn} \quad 0^{+}$ & ${ }^{57} \mathrm{Cu} \quad 3 / 2^{-}$ & ${ }^{56} \mathrm{Ni} 0^{+}$ & ${ }^{57} \mathrm{Ni} \quad 3 / 2^{-}$ & ${ }^{58} \mathrm{Ni} \quad 0^{+}$ & ${ }^{59} \mathrm{Ni} 3 / 2^{-}$ & ${ }^{60} \mathrm{Ni} \quad 0^{+}$ & ${ }^{61} \mathrm{Ni}$ & $3 / 2^{-}$ \\
\hline 29 & & ${ }^{62} \mathrm{As}^{+}$ & ${ }^{61} \mathrm{Ge}$ & $3 / 2^{-}$ & ${ }^{60} \mathrm{Ga} \quad 2^{+}$ & ${ }^{59} \mathrm{Zn} \quad 3 / 2^{-}$ & ${ }^{58} \mathrm{Cu} 1^{+}$ & ${ }^{59} \mathrm{Cu} \quad 3 / 2^{-}$ & ${ }^{60} \mathrm{Cu} 2^{+}$ & ${ }^{61} \mathrm{Cu} 3 / 2^{-}$ & ${ }^{62} \mathrm{Cu} \quad 1^{+}$ & & \\
\hline 30 & & ${ }^{64}$ Se $0^{+}$ & ${ }^{63} \mathrm{As}$ & $3 / 2^{-}$ & ${ }^{62} \mathrm{Ge} \quad 0^{+}$ & ${ }^{61} \mathrm{Ga} \quad 3 / 2^{-}$ & ${ }^{60} \mathrm{Zn} 0^{+}$ & ${ }^{61} \mathrm{Zn} 3 / 2^{-}$ & ${ }^{62} \mathrm{Zn} \quad 0^{+}$ & ${ }^{63} \mathrm{Zn} \mathrm{3/2}$ & ${ }^{64} \mathrm{Zn} \quad 0^{+}$ & & \\
\hline 31 & & & ${ }^{65} \mathrm{Se}$ & $3 / 2^{-}$ & ${ }^{64}$ As $0^{+}$ & ${ }^{63} \mathrm{Ge} \quad 3 / 2^{-}$ & ${ }^{62} \mathrm{Ga} 0^{+}$ & ${ }^{63} \mathrm{Ga} \quad 3 / 2^{-}$ & ${ }^{64} \mathrm{Ga} \quad 0^{+}$ & ${ }^{65} \mathrm{Ga} 3 / 2^{-}$ & & & \\
\hline 32 & & & ${ }^{67} \mathrm{Br}$ & $1 / 2^{-}$ & ${ }^{66} \mathrm{Se} \quad 0^{+}$ & ${ }^{65}$ As $3 / 2^{-}$ & ${ }^{64} \mathrm{Ge} 0^{+}$ & ${ }^{65} \mathrm{Ge} \quad 3 / 2^{-}$ & ${ }^{66} \mathrm{Ge} \quad 0^{+}$ & ${ }^{67} \mathrm{Ge} 1 / 2^{-}$ & & & \\
\hline 33 & & & ${ }^{69} \mathrm{Kr}$ & $5 / 2^{-}$ & ${ }^{68} \mathrm{Br} \quad 3^{+}$ & ${ }^{67}$ Se $5 / 2^{-}$ & ${ }^{66}$ As $0^{+}$ & ${ }^{67}$ As $5 / 2^{-}$ & ${ }^{68}{\mathrm{As} \quad 3^{+}}^{+}$ & ${ }^{69}$ As $5 / 2^{-}$ & & & \\
\hline 34 & & & ${ }^{71} \mathrm{Rb}$ & $5 / 2^{-}$ & ${ }^{70} \mathrm{Kr} \quad 0^{+}$ & ${ }^{69} \mathrm{Br} \quad 1 / 2^{-}$ & ${ }^{68}$ Se $0^{+}$ & ${ }^{69}$ Se $1 / 2^{-}$ & ${ }^{70}$ Se $\quad 0^{+}$ & ${ }^{71}$ Se $5 / 2^{-}$ & & & \\
\hline 35 & & & ${ }^{73} \mathrm{Sr}$ & $1 / 2^{-}$ & ${ }^{72} \mathrm{Rb} 3^{+} ?$ & ${ }^{71} \mathrm{Kr} \quad 5 / 2^{-}$ & ${ }^{70} \mathrm{Br} 0^{+}$ & ${ }^{71} \mathrm{Br} \quad 5 / 2^{-}$ & ${ }^{72} \mathrm{Br} 1^{+} ?$ & ${ }^{73} \mathrm{Br} 1 / 2^{-}$ & & & \\
\hline 36 & & & & & ${ }^{74} \mathrm{Sr} \quad 0^{+}$ & ${ }^{73} \mathrm{Rb} \quad 3 / 2^{-}$ & ${ }^{72} \mathrm{Kr} 0^{+}$ & ${ }^{73} \mathrm{Kr} \quad 3 / 2^{-}$ & ${ }^{74} \mathrm{Kr} \quad 0^{+}$ & & & & \\
\hline 37 & & & & & ${ }^{76} \mathrm{Y}$ & ${ }^{75} \mathrm{Sr} \quad 3 / 2^{-}$ & ${ }^{74} \mathrm{Rb} 0^{+}$ & ${ }^{75} \mathrm{Rb} \quad 3 / 2^{-}$ & ${ }^{76} \mathrm{Rb} 1^{-}$ & & & & \\
\hline 38 & & & & & ${ }^{78} \mathrm{Zr} \quad 0^{+}$ & ${ }^{77} \mathrm{Y} \quad 5 / 2^{+}$ & ${ }^{76} \mathrm{Sr} 0^{+}$ & ${ }^{77} \mathrm{Sr} \quad 5 / 2^{+}$ & ${ }^{78} \mathrm{Sr} \quad 0^{+}$ & & & & \\
\hline 39 & & & & & & ${ }^{79} \mathrm{Zr} \quad 5 / 2^{+}$ & ${ }^{78} \mathrm{Y} \quad 0^{+}$ & ${ }^{79} \mathrm{Y} \quad 5 / 2^{+}$ & & & & & \\
\hline 40 & & & & & & ${ }^{81} \mathrm{Nb} \quad 3 / 2^{-}$ & ${ }^{80} \mathrm{Zr} 0^{+}$ & ${ }^{81} \mathrm{Zr} \quad 3 / 2^{-}$ & & & & & \\
\hline 41 & & & & & & ${ }^{83} \mathrm{Mo} \mathrm{3/2}$ ? & ${ }^{82} \mathrm{Nb} 0^{+}$ & ${ }^{83} \mathrm{Nb} \mathrm{5/2+}$ ? & & & & & \\
\hline 42 & & & & & & ${ }^{85}$ Tс $1 / 2^{-}$ & ${ }^{84}{\mathrm{Mo} 0^{+}}^{+}$ & ${ }^{85} \mathrm{Mo} 1 / 2^{-}$ & & & & & \\
\hline 43 & & & & & & ${ }^{87} \mathrm{Ru} \quad 1 / 2^{-}$ & ${ }^{86}$ Tc $0^{+}$ & ${ }^{87}$ Тс $1 / 2^{-}$ & & & & & \\
\hline 44 & & & & & & ${ }^{89} \mathrm{Rh} \quad 7 / 2^{+}$ & ${ }^{88} \mathrm{Ru} 0^{+}$ & ${ }^{89} \mathrm{Ru} \quad 7 / 2^{+}$ & & & & & \\
\hline 45 & & & & & & ${ }^{91} \mathrm{Pd} \quad 7 / 2^{+}$ & ${ }^{90} \mathrm{Rh} 0^{+}$ & ${ }^{91} \mathrm{Rh} \quad 7 / 2^{+}$ & & & & & \\
\hline 46 & & & & & & ${ }^{93} \mathrm{Ag} \quad 9 / 2^{+}$ & ${ }^{92} \mathrm{Pd} 0^{+}$ & ${ }^{93} \mathrm{Pd} \quad 9 / 2^{+}$ & & & & & \\
\hline 47 & & & & & & ${ }^{95} \mathrm{Cd} \quad 9 / 2^{+}$ & ${ }^{94} \mathrm{Ag} 0^{+}$ & ${ }^{95} \mathrm{Ag} \quad 9 / 2^{+}$ & & & & & \\
\hline 48 & & & & & & ${ }^{97} \operatorname{In} \quad 9 / 2^{+}$ & ${ }^{96} \mathrm{Cd} 0^{+}$ & ${ }^{97} \mathrm{Cd} \quad 9 / 2^{+}$ & & & & & \\
\hline 49 & & & & & & ${ }^{99} \mathrm{Sn} \quad 9 / 2^{+}$ & ${ }^{98} \mathrm{In}$ & ${ }^{99} \operatorname{In} \quad 9 / 2^{+}$ & & & & & \\
\hline
\end{tabular}

"Not include the mirror nuclei $n>5$, which satisfy the identity as the cases in the table. 


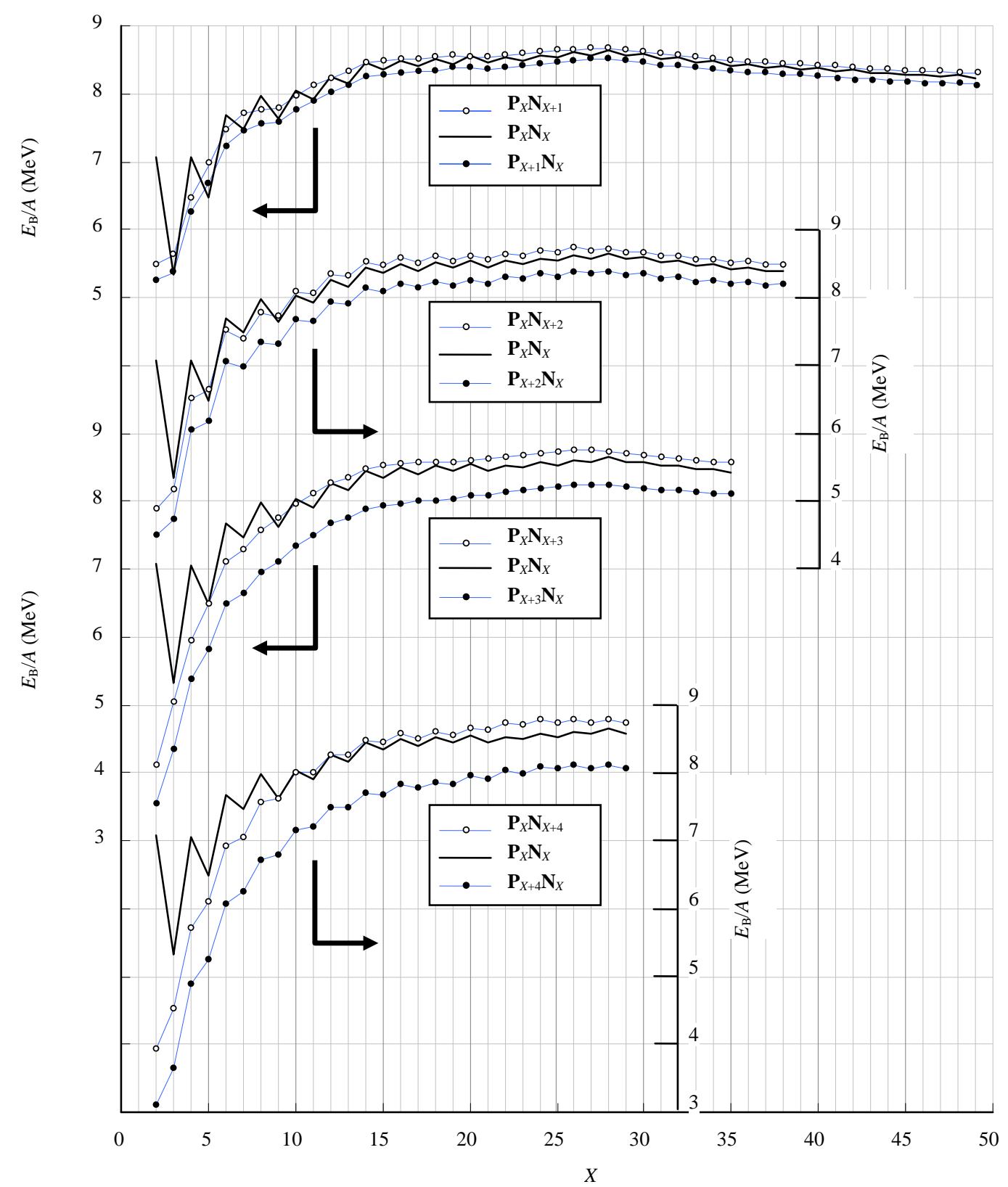

Figure 7. The comparison of $E_{\mathrm{B}} / A$ for mirror nuclei with the number of extra nucleon $n=1,2,3$ and 4 (from top to bottom). For each case, the $E_{\mathrm{B}} / A$ difference between mirror nuclei is nearly a constant. When $n=1,3$, the curves are smooth; when $n=2,4$, they become zigzag.

when $n$ is even. The $E_{\mathrm{B}} / A$ difference between the pair is nearly a constant of $0.184 n \mathrm{MeV}$.

\section{Acknowledgements}

The authors thank Prof. Jubo Zhu and Prof. Jianshu Luo for their effort in mathematical proof as well as many valuable discussions with Qinghua Wang, Tianjiao Hu and Zhenghua Jiang.

\section{References}

[1] Rowe, D.J. and Wood, J.L. (2010) Fundamentals of Nuclear Models, Foundational Models. World Scientific, Hackensack. http://dx.doi.org/10.1142/6209 
[2] Martin, B.R. (2009) Nuclear and Particle Physics, an Introduction. 2nd Edition, Wiley, Hoboken.

[3] Audi, G., Wapstra, A.H. and Thibault, C. (2003) The AME2003 Atomic Mass Evaluation (II). Tables, Graphs and References. Nuclear Physics A, 729, 337-676. http://dx.doi.org/10.1016/j.nuclphysa.2003.11.003

[4] Audi, G., Bersillon, O., Blachot, J. and Wapstra, A.H. (2003) The NUBASE Evaluation of Nuclear and Decay Properties. Nuclear Physics A, 729, 3-128. http://dx.doi.org/10.1016/j.nuclphysa.2003.11.001

[5] Holden, N.E. (2004) Table of the Isotopes. In: Lide, D.R., Ed., CRC Handbook of Chemistry and Physics, 85th Edition, CRC Press, Boca Raton.

[6] Hansen, P.G. and Jonson, B. (1987) The Neutron Halo of Extremely Neutron-Rich Nuclei. Europhysics Letters, 4, 409414. http://dx.doi.org/10.1209/0295-5075/4/4/005

[7] Wilson R.R. (1952) Radii of Mirror Nuclei. Physical Review, 88, 350-351. http://dx.doi.org/10.1103/PhysRev.88.350

[8] Ivanter I.G. and Troitski M.A. (1964) Mass Difference of Mirror Nuclei. Journal of Experimental and Theoretical Physics, 47, 1773-1776.

[9] Ajzenberg-Selove, F. (1996) Energy Levels of Light Nuclei A=13-15. Nuclear Physics A, 523, 1-196. http://dx.doi.org/10.1016/0375-9474(91)90446-D

[10] Bentley, M.A., et al. (2006) High-Spin Spectroscopy of Natural and Unnatural Parity States in the Mirror-Pair ${ }^{45} \mathrm{~V} /{ }^{45} \mathrm{Ti}$. Physical Review C, 73, 1-10.

[11] Usoskin, L.G. and Kovalsov, G.A. (2008) Production of cosmogenic ${ }^{7}$ Be isotope in the atmosphere: Full 3-D modeling. Journal of Geophysical Research, 113, 1-12.

\section{Methods}

1. The nucleon coordinates $(x, y, z)$ for the nuclei in Figure 2

(P: bold, $\mathbf{N}$ : normal, extra $\mathbf{N}$ : in parenthesis)

${ }^{6} \mathrm{Li} \quad \mathbf{0 , 0 , 0} \& \mathbf{1 , 1 , 0} \& \mathbf{0 , 1}, 1$ \& 1,0,0 \& 1,1,1 \& 0,0,1

${ }^{7} \mathrm{Li} \quad$ ibid \& $(0,1,0)$

${ }^{11} \mathrm{Li}$ ibid \& $(2,1,0) \&(0,1,2) \&(0,-1,0) \&(1,2,0)$

${ }^{10} \mathrm{~B} \quad \mathbf{0 , 0 , 0} \& \mathbf{1 , 0 , 1} \& \mathbf{2 , 1 , 1} \& \mathbf{1 , 2 , 1} \& \mathbf{1 , 1 , 0} \& 1,0,0$ \& 1,1,1 \& 2,2,1 \& 1,2,0 \& 0,1,0

${ }^{11} \mathrm{~B}$ ibid \& $(0,0,1)$

${ }^{14} \mathrm{~N} \quad \mathbf{0 , 0} 0$ \& $\mathbf{0 , 1}, 1$ \& 1,0,1 \& 2,1,1 \& 3,1,0 \& 2,0,0 \& 1,1,0 \& 0,0,1 \& 1,1,1 \& 2,0,1 \& 3,1,1 \& 3,0,0 \& 2,1,0 $\& 1,0,0$

${ }^{15} \mathrm{~N}$ ibid \& $(0,1,0)$

${ }^{18} \mathrm{~F} \quad \mathbf{1 , 0 , 0} \& \mathbf{2 , 0 , 1} \& \mathbf{3 , 1}, 1$ \& 2,1,0 \& 2,2,1 \& 1,3,1 \& 0,3,0 \& 1,2,0 \& 1,1,1 \& 2,0,0 \& 3,0,1 \& 2,1,1 \& 2,2,0

\& 2,3,1 \& 1,3,0 \& 0,2,0 \& 1,2,1 \& 1,1,0

${ }^{19} \mathrm{~F}$ ibid \& $(1,0,1)$

${ }^{8} \mathrm{Be} \quad \mathbf{0 , 0 , 0} \& \mathbf{1 , 1 , 0} \& \mathbf{2 , 1 , 1} \& \mathbf{1 , 0 , 1} \& 1,0,0$ \& 2,1,0 \& 1,1,1 \& 0,0,1

${ }^{9} \mathrm{Be}$ ibid \& $(2,0,1)$

${ }^{12} \mathrm{C} \quad \mathbf{1 , 0 , 0} \& \mathbf{2 , 1 , 0} \& \mathbf{3 , 1 , 1} \& \mathbf{2 , 2 , 1} \& \mathbf{1 , 1 , 1} \& \mathbf{0 , 1}, 0$ \& 2,0,0 \& 3,1,0 \& 2,1,1 \& 1,2,1 \& 0,1,1 \& 1,1,0

${ }^{13} \mathrm{C}$ ibid \& $(1,0,1)$

${ }^{16} \mathrm{O} \quad \mathbf{1 , 0 , 0} \& \mathbf{2 , 0 , 1} \& \mathbf{2 , 1 , 0} \& \mathbf{3 , 1 , 1} \& \mathbf{2 , 2 , 1} \& \mathbf{1 , 2}, 0$ \& 1,1,1 \& $\mathbf{0 , 1 , 0} \&$ 1,0,1 \& 2,0,0 \& 3,1,0 \& 2,1,1 \& 2,2,0

$\& 1,2,1 \& 0,1,1 \& 1,1,0$

${ }^{17} \mathrm{O}$ ibid \& $(0,0,0)$

${ }^{18} \mathrm{O}$ ibid \& $(3,2,1)$

The coordinates are determined according to the rules:

1) Even $Z$ ring nuclei are center-symmetrical, indistinguishable when $P$ and $N$ interchange.

2) Odd-Z ring nuclei are antisymmetrical.

3) Avoid the structures that may split into two normal rings if possible. 
4) Be of smallest radius of gyration $\left[R^{2}\right]^{0.5}$.

5) Extra $\mathrm{N}$ is bound by 2 or more ring P's, high abundance isotopes are generally bound by 3 P's.

2. The proof: “odd- $Z$ rings have separated gravity centers of $P$ and $N$ ”

A ring with ZP's and ZN's is arranged as $\mathbf{P}-\mathbf{N}$ alternating connections in Cartesian coordinate, where the distance between two bound nucleons is 1 unit, and the adjacent connection lines perpendicular to each other. Let any of a $\mathbf{P}$ be $A_{1}$ at $(0,0,0)$, while $A_{2}$ (an $\left.\mathbf{N}\right)$ is at one of 6 possible coordinates: $( \pm 1,0,0)$ or $(0, \pm 1,0)$ or $(0,0, \pm 1)$.

For any $A_{i}$, the Equations (1) and (2) must be satisfied.

$$
\begin{aligned}
& \left(x_{i}+y_{i}+z_{i}\right)-\left(x_{i-1}+y_{i-1}+z_{i-1}\right)= \pm 1 \\
& x_{i}+y_{i}+z_{i}=\left\{\begin{array}{l}
\text { even }(\text { if } i \text { is odd }) \\
\text { odd }(\text { if } i \text { is even })
\end{array}\right.
\end{aligned}
$$

when $Z$ is an odd number, if the gravity center of $\mathbf{P}(i=1,3,5, \cdots, 2 Z-1)$ were superimposed with that of $\mathbf{N}(i$ $=2,4,6, \cdots, 2 Z$ ), the following equations must be satisfied.

Then, the necessary condition for the superimposition is

$$
\begin{aligned}
& \frac{1}{Z} \sum_{i=1,3,5, \cdots, 2 Z-1} x_{i}=\frac{1}{Z} \sum_{j=2,4,6, \cdots, 2 Z} x_{j} \\
& \frac{1}{Z} \sum_{i=1,3,5, \cdots, 2 Z-1} y_{i}=\frac{1}{Z} \sum_{j=2,4,6, \cdots, 2 Z} y_{j} \\
& \frac{1}{Z} \sum_{i=1,3,5, \cdots, 2 Z-1} Z_{i}=\frac{1}{Z} \sum_{j=2,4,6, \cdots, 2 Z} Z_{j}
\end{aligned}
$$

Adding Equations (3), (4) and (5), the resulted Equation (6) is the necessary condition for the superimposition.

$$
\sum_{i=1,3,5, \cdots, 2 Z-1} x_{i}+y_{i}+z_{i}=\sum_{j=2,4,6, \cdots, 2 Z} x_{j}+y_{j}+z_{j}
$$

However, the left side of Equation (6) must be even, while the right side must be odd. Obviously, the Equation (6) is impossible. Therefore, for odd $Z$ ring, the gravity centers of $\mathbf{P}$ and $\mathbf{N}$ must be separated.

3. Calculation of gravity center of $n$ nucleons, $x_{g}, y_{g}$ and $z_{g}$

$$
\begin{aligned}
& x_{g}=\frac{1}{n} \sum_{i=1}^{n} x_{i} \\
& y_{g}=\frac{1}{n} \sum_{i=1}^{n} y_{i} \\
& z_{g}=\frac{1}{n} \sum_{i=1}^{n} z_{i}
\end{aligned}
$$

\section{Calculation of radius of gyration of a nucleus with $\boldsymbol{A}$ nucleons}

$$
\left[R^{2}\right]^{0.5}=\sqrt{\frac{1}{A} \sum_{i=1}^{A}\left(x_{i}-x_{g}\right)^{2}+\left(y_{i}-y_{g}\right)^{2}+\left(z_{i}-z_{g}\right)^{2}}
$$

$x_{\mathrm{g}}, y_{\mathrm{g}}$ and $z_{\mathrm{g}}$ are the coordinate of gravity center of the nuclide.

\section{Calculation of the separation of gravity centers of $\mathbf{P}$ and $\mathbf{N}$}

$$
D_{g(\mathbf{P N})}=\sqrt{\left(x_{g(\mathbf{P})}-x_{g(\mathbf{N})}\right)^{2}+\left(y_{g(\mathbf{P})}-y_{g(\mathbf{N})}\right)^{2}+\left(z_{g(\mathbf{P})}-z_{g(\mathbf{N})}\right)^{2}}
$$

$x_{\mathrm{g}}, y_{\mathrm{g}}$ and $z_{\mathrm{g}}$ with subscript $(\mathbf{P})$ and $(\mathbf{N})$ are the coordinates of gravity center of all $\mathbf{P}$ 's and all $\mathbf{N}$ 's in a nucleus respectively. 
Scientific Research Publishing (SCIRP) is one of the largest Open Access journal publishers. It is currently publishing more than 200 open access, online, peer-reviewed journals covering a wide range of academic disciplines. SCIRP serves the worldwide academic communities and contributes to the progress and application of science with its publication.

Other selected journals from SCIRP are listed as below. Submit your manuscript to us via either submit@scirp.org or Online Submission Portal.
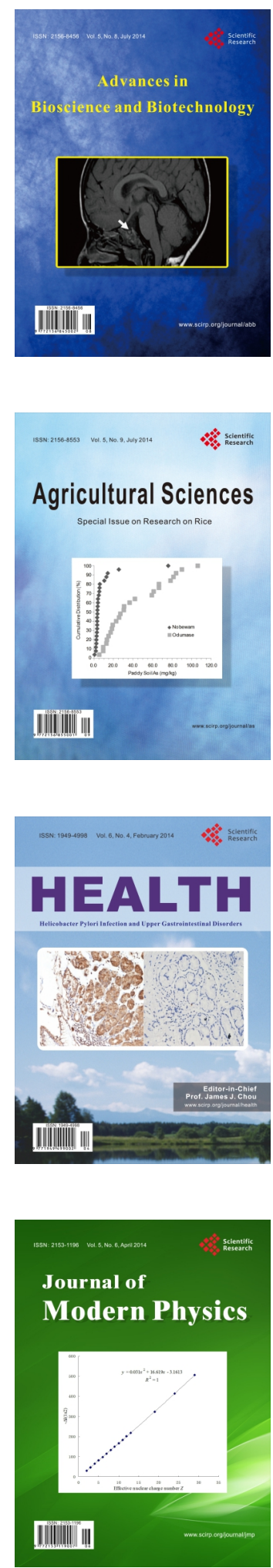
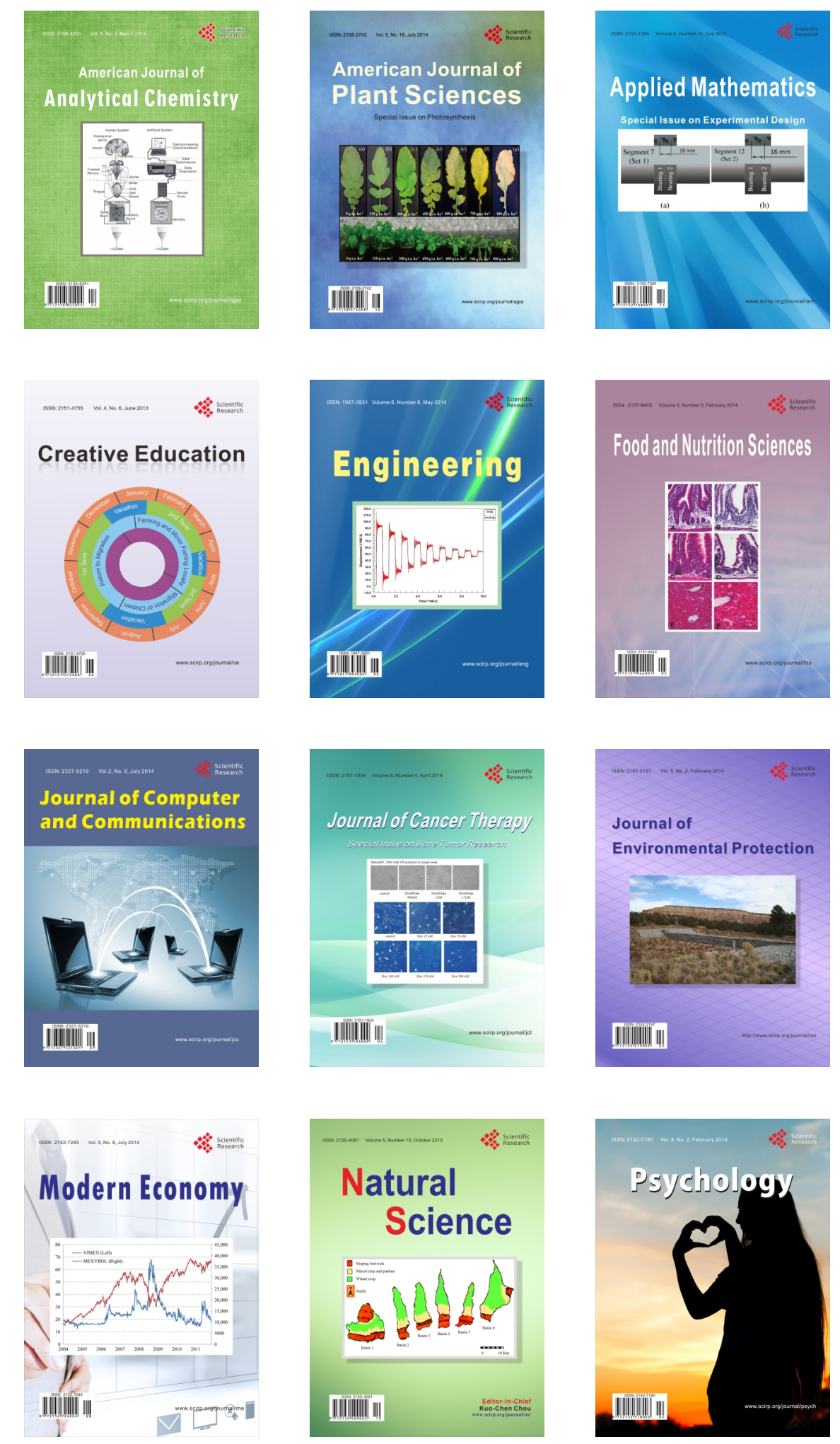